\title{
Technical note: Unresolved aspects of the direct vapor equilibration method for stable isotope analysis $\left(\delta^{18} \mathrm{O}\right.$, $\left.\delta^{2} \mathbf{H}\right)$ of matrix-bound water: unifying protocols through empirical and mathematical scrutiny
}

\author{
Benjamin Gralher, Barbara Herbstritt, and Markus Weiler \\ Chair of Hydrology, University of Freiburg, Freiburg 79098, Germany \\ Correspondence: Benjamin Gralher (benjamin.gralher@googlemail.com)
}

Received: 11 May 2021 - Discussion started: 17 May 2021

Revised: 21 August 2021 - Accepted: 24 August 2021 - Published: 27 September 2021

\begin{abstract}
The direct vapor equilibration laser spectrometry (DVE-LS) method has been developed for obtaining matrixbound water stable isotope data in soils, the critical zone, and bedrock, deriving therefrom subsurface water flow and transport processes and, ultimately, characterizing, for example, groundwater recharge and vulnerability. Recently, DVE-LS has been increasingly adopted due to its possible high sample throughput, relative simplicity, and cost-efficiency. However, this has come at the cost of a non-unified standard operation protocol (SOP), and several contradictory suggestions regarding protocol details do exist which have not been resolved to date. Particularly, sample container material and equilibration times have not yet been agreed upon. Beside practical constraints, this often limits DVE-LS applicability to interpreting relative isotope dynamics instead of absolute values. It also prevents data comparability among studies or laboratories, and several previous comparisons of DVELS with other, more traditional approaches of water extraction and subsequent stable isotope analysis yielded significant discrepancies for various sample matrices and physical states. In a series of empirical tests, we scrutinized the controversial DVE-LS protocol details. Specifically, we tested 10 different easily available and cost-efficient inflatable bags previously employed or potentially suitable for DVE-LS sample collection and equilibration. In storage tests similar to the DVE-LS equilibration process but lasting several weeks, we quickly found heat-sealed bags made of laminated aluminum (Al) sheets to be superior by several orders of magnitude over more frequently used freezer bags in terms of evaporation safety and accompanying adverse isotope effects. For
\end{abstract}

the first time, Al-laminated bags allow the applied equilibration time to be adapted exclusively to sample requirements instead of accepting reduced data quality in a trade-off with material shortcomings. Based on detailed physical considerations, we further describe how to calculate the minimum available container headspace and sample-contained liquid water volume and how their ratio affects analytical precision and accuracy. We are confident that these guidelines will expand DVE-LS applicability and improve data quality and comparability among studies and laboratories by contributing to a more unified, physically well-founded SOP based on more appropriate components.

\section{Introduction}

The direct vapor equilibration laser spectrometry (DVE-LS) method first published by Wassenaar et al. (2008) has facilitated a way for fairly convenient, high-throughput stable isotope analysis of water bound to the soil matrix, rocks, or plant tissue. Instead of physically extracting water, the method employs analysis of a corresponding vapor phase and thereby bypasses many of the previously necessary, laborious sample preparation steps. At the same time, it increases the number of samples that can be processed per day. It employs inflatable sample containers into which evaporation-susceptible soil, rock, or plant samples of interest are quickly collected. Following sample collection, the containers are commonly inflated with a dry inflation atmosphere and sealed. Then 
they are left for isothermal isotope equilibration between the matrix-bound liquid water reservoir of interest and the container headspace atmosphere vapor prior to the direct, yet non-automated analysis of the water vapor via laser-based isotope spectrometry. A schematic drawing of the DVE-LS methodic steps is shown in Fig. 1. Co-measured calibration standards are referenced to the VSMOW-SLAP scale (Craig, 1961) and prepared accordingly following the principle of identical treatment (PIT) (Werner and Brand, 2001). They allow for straightforward calculation of sample liquid water stable isotope signatures from the standards' known liquid water isotope signatures and raw headspace water vapor isotope readings of standards and samples.

The growing distribution of laser-based water stable isotope analyzers in recent years and the DVE-LS method's relative simplicity, resulting from fairly little sample preparation workload, low-cost consumables, and omission of sophisticated water extraction lines and analyzer peripherals, enabled its rapid, widespread adoption. It has now been employed to investigate a long list of processes and phenomena in hydrology, ecohydrology, pedology, hydrogeology, and related disciplines spanning the entire plant-soil-groundwater continuum in various climates. Unlike, for example, suction cups or mechanical squeezing, DVE-LS is assumed to provide isotope data that are not tension-specific but represent the bulk water of a given sample (Sprenger et al., 2015a). On the hillslope scale, the DVE-LS method has been used to reveal present and past subsurface water flow paths in the unsaturated and saturated zone of humid (Garvelmann et al., 2012) or alpine regions (Mueller et al., 2014). On a similar scale, it has been used to obtain high-resolution water isotope depth profiles for the investigation of spatial and temporal dynamics of water flow and solute transport in a heterogeneous glacial till (Stumpp and Hendry, 2012). Sprenger et al. (2015b) used it to test and compare different modeling strategies to determine soil water flow and solute transport parameters. On the regional scale, it was employed to quantify the spatiotemporal variability in tree water uptake (Bertrand et al., 2014), to evaluate aquifer recharge and vulnerability in an alluvial lowland (Filippini et al., 2015), to assess snowmelt-dominated groundwater recharge in a northern region (Chesnaux and Stumpp, 2018; Boumaiza et al., 2020), and to feed a groundwater recharge model for ungauged watersheds (Mattei et al., 2020). With the help of DVE-LS data from the shallow subsurface, the impacts of the 2018 drought in central Europe and its recovery on subsurface water stress, water ages, and ecohydrologic fluxes were understood and simulated (Kleine et al., 2020; Smith el al., 2020). In the deep saturated zone, the DVE-LS method helped to interpret high-resolution depth profiles and thus retrace paleogroundwater flow and long-term transport processes in aquitards (e.g., Hendry and Wassenaar, 2009, 2011; Hendry et al., 2011a, 2013; Harrington et al., 2013). In all these examples DVE-LS analyses were performed on soil or rock samples. Although generally conceivable (Millar et al.,
2018, 2019), we are not aware of any published field study employing DVE-LS on plant samples.

In principle, the DVE-LS method rests upon analyzing a corresponding vapor phase instead of the liquid water reservoir of interest itself. Meanwhile, this working principle has been transferred even to continuous, minimally invasive in situ approaches of stable isotope analysis of water that is either freely flowing (Munksgaard et al., 2011; Koehler and Wassenaar, 2011; Herbstritt et al., 2012) or bound to the matrix of soils (Rothfuss et al., 2013; Volkmann and Weiler, 2014) or plant xylems (Volkmann et al., 2016). The calibration of isotope data obtained this way has also been aided in some cases via DVE-LS analyses of carefully prepared standards (e.g., Oerter et al., 2016).

The DVE-LS method employs laser-based isotope analysis. It therefore does not come completely without complications. Generally, it has been demonstrated that laserbased stable isotope analyzers are susceptible to the influence of gaseous contaminants like alcohols (Brand et al., 2009; Martín-Gómez et al., 2015), which may be emitted from plant samples, or $\mathrm{H}_{2} \mathrm{~S}$ (Malowany et al., 2015) or methane (Hendry et al., 2011b), which may appear in anoxic or contaminated sites. Accordingly, this is also relevant for DVE-LS analyses performed on samples from such origins. Hendry et al. (2011b) described and tested a correction algorithm applicable for analyzers based on cavity ring-down spectrometry (CRDS) that are exposed to naturally occurring methane levels. For samples contaminated with methanol or ethanol, Martín-Gómez et al. (2015) compared a selfdeveloped post-processing software with an online oxidation oven (Micro-Combustion Module, Picarro) physically implemented into the measurement process of a Picarro L2120$i$ and were able to correct or remove considerable levels of these contaminants. However, they did not test their setup for DVE-LS analyses. The impact of changing background gas matrices, which may happen due to, for example, ongoing microbial activity in natural soil samples, has been investigated by Gralher et al. (2016). They also presented a postcorrection scheme of potentially affected DVE-LS samples based on an analyzer-recorded spectral variable and measurement iterations (Gralher et al., 2018).

Overall, the DVE-LS method has considerably simplified matrix-bound water stable isotope analysis. However, it is not yet perfect, and several studies have aimed at specifically testing and/or improving accuracy, precision, and/or the general applicability of the protocol originally described by Wassenaar et al. (2008), e.g., by comparison with other methods of matrix-bound water stable isotope analysis. Hendry et al. (2015) compared DVE-LS results against isotope analyses of water obtained from piezometers and mechanical squeezing of geologic core samples. They suggested spiking the employed drilling fluid with ${ }^{2} \mathrm{H}$ to detect contamination of original pore water which they observed, for example, in samples from saturated, highly permeable geologic media. They also tested different sample storage containers and favored 


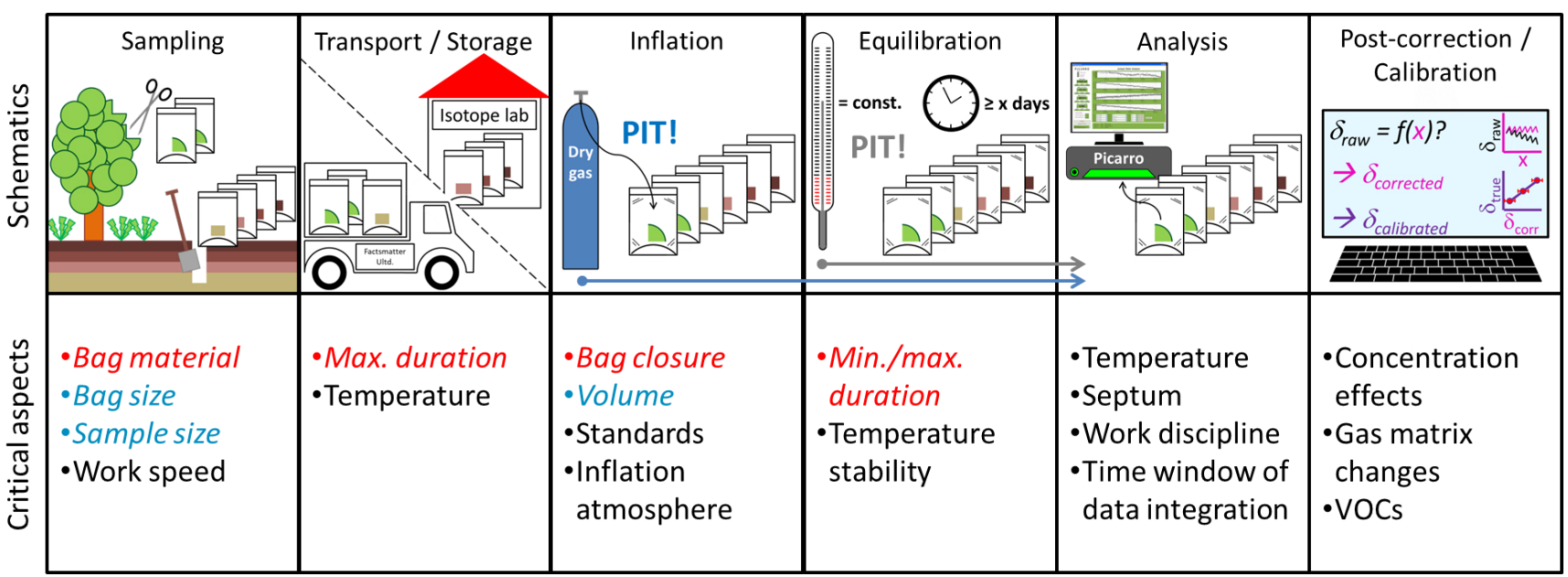

Figure 1. Schematics and critical aspects of the DVE-LS methodic steps. Aspects quantitatively investigated in this study are highlighted in red (empirical) and blue (mathematical).

Ziploc ${ }^{\circledR}$ freezer bags, which when doubled they found to reliably hold sample water and prevent significant evaporitic enrichment of heavy isotopes for up to $10 \mathrm{~d}$. Comparing the DVE-LS method with analyses of liquid water squeezed from low-permeability samples, Nakata et al. (2018) found the former to represent water from open pores only. Millar et al. (2018) analyzed plant samples from a controlled environment in a direct comparison of the DVE-LS method against five quantitative water extraction methods. They found the former to be superior in terms of limited co-extraction of volatile organic compounds (VOCs), rapid sample throughput, and near-instantaneously returned stable isotope results. They reported, however, that the DVE-LS method systematically yielded water stable isotope signatures somewhat enriched in ${ }^{2} \mathrm{H}$ and ${ }^{18} \mathrm{O}$ content.

Mattei et al. (2019) scrutinized the DVE-LS method on an analyzer employing off-axis integrated cavity output spectrometry (OA-ICOS). For the projected calibration of samples, they investigated Fold-A-Carrier Reliance ${ }^{\mathrm{TM}}$ bags (Reliance Products, Winnipeg, Canada) of $20 \mathrm{~L}$ volume filled with $20 \mathrm{~mL}$ water aliquots. They found the bags to retain $99 \%$ of the injected water over the course of $30 \mathrm{~d}$. They highlighted the possibility of many measurement iterations at the cost, however, of a high consumption of standard water volume. They also addressed vapor concentration effects on their instrument which caused high variabilities in isotope readings between different combinations of water vaporizing methods and modes of analyzer operation. Testing their approach on oven-dried and rewetted soil aliquots, they found isotope readings to reach plateaus after $6 \mathrm{~d}$ of equilibration. Such soil aliquots were also used by Wang et al. (2019), who tested different isotope data correction strategies, including one incorporating soil physical variables, namely relative clay and water content. They suggested that the correction strategy should be adapted to the research focus of iso- tope assays and gave the example of groundwater vs. root water uptake. Using Ziploc ${ }^{\circledR}$ freezer bags, they defined the optimum equilibration time to be $12-24 \mathrm{~h}$ and argued that longer equilibration times should be avoided due to the onset of evaporitic enrichment of heavy isotopes afterwards.

Ziploc ${ }^{\circledR}$ bags as employed in the original DVE-LS study (Wassenaar et al., 2008) are used by many research groups. They are resealable, inflatable, considered sufficiently leaktight, and collapsible as demanded. Eventually tested alternatives fulfilling the same criteria have been found to be prohibitive for large-scale applications. However, a Ziploc $®$ bag's diffusional barrier is clearly not absolute and thus restricts proposed maximum equilibration times. It stands out that suggested maximum equilibration times vary considerably. They range from $24 \mathrm{~h}$ (Wang et al., 2019) to $10 \mathrm{~d}$ (Hendry et al., 2015). Notably, they are consistently substantiated by water loss and accompanying adverse effects on isotope data upon exceedance. This may be indicative of differences in the bags' production processes and/or their storage conditions during the respective investigations. Either way, this is not satisfying as it makes suggestions obtained this way not generally transferable between laboratories. Also, ideal equilibration times should not be defined by the containers' shortcomings but exclusively by the samples' properties and best possible data quality. This holds also for extreme soil physical settings regarding, for example, sample permeability or size.

Despite the large number of studies aiming at improving the DVE-LS method, only Hendry et al. (2015) combined headspace isotope analyses and weight loss observations on identical samples. And to date, no material has been scrutinized that is suitable for DVE-LS sample bags and allows for storage times which are not restricted by the bags' shortcomings while at the same time still coming at reasonable per-unit costs and additionally fulfilling all criteria 
listed above. Such bags would also simplify the sample handling process prior to equilibration. They would dispense with additional workload and potential pitfalls in cases of restricted or delayed laboratory access. In such a case, Ziploc ${ }^{\circledR}$ bags require extra measures like, for example, evaporationsusceptible sample transfer from evaporation-safe containers such as glass jars (Mattei et al., 2019) or precautionary deposition in coolers (Wassenaar et al., 2008). Evaporation-proof sample bags would also allow for the calculation of minimum sample sizes based exclusively on physical requirements and thus likely expand the applicability of the DVE-LS method regarding the range of potential sample size, matrices, and physical states. Finally, they would expand the DVELS method's reliability in terms of interpreting absolute isotope values instead of being limited to relative dynamics in the case of, for example, deuterium-labeled samples, quickly inducing adverse isotope effects due to extraordinarily high vapor pressure gradients across container walls on the isotopologue level. In summary, no unified standard operation procedure (SOP) exists to date. Unfortunately, this bears the risk that unsuitable protocol details are applied in inappropriate cases.

Therefore, the aim of this study was to further improve the trustworthiness of DVE-LS data and to allow comparability across laboratories by finding improved components and contributing to a more unified SOP. Specifically, we wanted to experimentally identify better, yet affordable materials for DVE-LS sample storage containers. Then, we determined minimum and maximum storage and equilibrium times that are not dictated by gradual water loss and evaporitic enrichment of heavy isotopes. We simulated potential evaporative water losses with a Rayleigh-type approach. Finally, we aimed at mathematically assessing reasonable container and sample sizes which we deem necessary for obtaining accurate and precise DVE-LS-derived isotope data of matrix-bound water reservoirs.

\section{Method}

\subsection{Empirical observations}

\subsubsection{Material selection}

In the first part of our study, we intended to get an overview of different bags that are potentially suitable for DVE-LS. Consequently, we were looking for materials that can be used to build airtight, inflatable, collapsible, and resealable bags as originally demanded by Wassenaar et al. (2008). Our investigations focused on food storage products due to their widespread use and resulting easy availability and relative inexpensiveness. We finally obtained 10 different bags from commercial sources including those previously used for DVE-LS applications and two custom-made bags from local fish and meat vendors, originally intended for keeping their products isolated and odorless after hand-out to customers. With these bags we closely simulated the originally proposed DVE-LS protocol. Specifically, all bags were filled with 233 to $380 \mathrm{~g}$ of field-moist soil, inflated, and closed by means of an integrated zip closure where available, via heat-sealing if accordingly designed or with Teflon (PTFE) sealing tape (Petri-Seal ${ }^{\mathrm{TM}}$, Sigma-Aldrich) otherwise. The bags were left on the laboratory bench in a temperaturecontrolled environment $\left(20^{\circ} \mathrm{C} \pm 1{ }^{\circ} \mathrm{C}\right)$ exposed to ambient air (RH: $11.8 \%-83.1 \%$; mean: $42.3 \% \pm 11.6 \%$ ) and occasionally weighed (PT3100, Sartorius, Göttingen, Germany, https://www.sartorius.com, last access: 21 September 2021; resolution: $0.1 \mathrm{~g}$ ) over the course of up to $71 \mathrm{~d}$. This part of the study was conducted on unique items and served as a pre-test to the actual assessment of isotope effects potentially complicating DVE-LS analyses. A list of characteristics of the bags used in this part of our investigations can be found in Table 1.

\subsubsection{Weight losses and stable isotope effects}

In the second part of the study we focused on quantitatively assessing the effects of selected storage bags on DVE-LSbased stable isotope analysis of matrix-bound water. For this purpose, we reduced the number of different bags but increased the number of replicates. We selected bag candidates that spanned the largest part of the weight losses observed in the first part of the study. Additional, rather pragmatic aspects of this selection process were the bags' ruggedness and expected ease of handling during projected, time-critical collection of large numbers of evaporation-susceptible soil, rock, or plant samples in the field. In total, 21 replicates of each of these bag candidates were then equipped on one side with silicone blots or adhesive tape, which served as custommade septa during direct headspace analyses. In order to account for outgassing of VOCs from freshly applied silicone, thus compromising isotope readings, this step was conducted well in advance ( $\geq 2 \mathrm{~d}$ ) of the isotope analyses. This time we differed from the original DVE-LS protocol by omitting the soil. Instead, all bags were filled with $5 \mathrm{~mL}$ of isotopically identical pure water aliquots, inflated with dry air, sealed immediately thereafter, and weighed (PCB2500-2, Kern \& Sohn, Balingen, Germany, https://www.kern-sohn.com, last access: 21 September 2021; resolution: $0.01 \mathrm{~g}$ ). Again, the bags were left in a temperature-controlled environment and exposed to ambient air. After 1, 2, 5, 9, 14, 21, and $28 \mathrm{~d}$, successive subsets of three replicates of all bag versions were weighed again, and their headspace water vapor stable isotope signatures $\left(\delta^{18} \mathrm{O}\right.$ and $\left.\delta^{2} \mathrm{H}\right)$ were determined.

Isotope analysis was facilitated by puncturing the bags through the previously applied septa with a hollow needle directly connected via $1 / 8^{\prime \prime}$ Teflon (PFA) tubing to the sample inlet port of the cavity ring-down isotope analyzer (L2120$i$, Picarro Inc., Santa Clara, CA, USA, https://www.picarro. com, last access: 21 September 2021). On each day of analy- 
Table 1. Characteristics of the different bags tested in the first part of this study. LDPE: low-density polyethylene. PET: polyethylene terephthalate. PE: polyethylene. Al: aluminum.

\begin{tabular}{|c|c|c|c|c|c|c|c|}
\hline Bag ID & $\begin{array}{l}\text { Commercial product } \\
\text { name and } \\
\text { manufacturer }\end{array}$ & Material type & $\begin{array}{r}\text { Material } \\
\text { thickness } \\
(\mu \mathrm{m})\end{array}$ & $\begin{array}{l}\text { Closing } \\
\text { mechanism }\end{array}$ & $\begin{array}{r}\text { Water vapor } \\
\text { permeability } \\
\text { (manufacturer information) }\end{array}$ & $\begin{array}{r}\text { Dimensions } \\
(\mathrm{W} \times \mathrm{H} ; \mathrm{cm})\end{array}$ & $\begin{array}{r}\text { Approx. } \\
\text { volume } \\
(\mathrm{L})\end{array}$ \\
\hline $\mathrm{G} \& \mathrm{G}$ & $\begin{array}{l}\text { Gut \& Günstig } \\
\text { Gefrierbeutel }\end{array}$ & LDPE & 70 & Zip closure & $1 \mathrm{~g}\left(\mathrm{~m}^{2} \mathrm{~d}\right)^{-1^{\mathrm{a}}}$ & $17.5 \times 20.5$ & 1.0 \\
\hline $\mathrm{FF} 1$ & Fish packaging foil ${ }^{\mathrm{MIG}}$ & Al-steamed plastic & $\begin{array}{r}\text { Total: } 60 \\
\text { Al: NA }\end{array}$ & Heat-sealed & NA & $15 \times 30$ & 2.0 \\
\hline toppits & $\begin{array}{l}\text { Toppits }{ }^{\circledR} \\
\text { Gefrierbeutel }{ }^{\mathrm{Cof}}\end{array}$ & LDPE & 100 & Double Ziploc® & $1 \mathrm{~g}\left(\mathrm{~m}^{2} \mathrm{~d}\right)^{-1^{\mathrm{a}}}$ & $17.5 \times 20.5$ & 1.0 \\
\hline $\mathrm{SBz} \_\mathrm{t}$ & $\mathrm{CB} 400-524 \mathrm{Vtz} \mathrm{WP}^{\mathrm{WP}}$ & PET-PE-LDPE & Total: 130 & $\begin{array}{l}\text { Zip closure and } \\
\text { PTFE tape }\end{array}$ & $0.4 \mathrm{~g}\left(100 \mathrm{in}^{2} \mathrm{~d}\right)^{-1^{b}}$ & $20 \times 27$ & 2.4 \\
\hline FF2 & Fish packaging foil ${ }^{\mathrm{WP}}$ & $\mathrm{Al}$ - or plastic-coated paper & $\begin{array}{r}\text { Total: } 95 \\
\text { Al: NA }\end{array}$ & Heat-sealed & NA & $17 \times 30$ & 2.5 \\
\hline s_Al3z & CB400-311BRZ ${ }^{\mathrm{WP}}$ & PET-Al-LDPE & $\begin{array}{r}\text { Total: } 127 \\
\text { Al: } 7.1\end{array}$ & Zip closure & $<0.02 \mathrm{~g}\left(100 \mathrm{in}^{2} \mathrm{~d}\right)^{-1^{\mathrm{b}}}$ & $13.5 \times 18.5$ & 0.8 \\
\hline $\mathrm{Al} 3 \mathrm{z}$ & CB400-420GBZ ${ }^{W P}$ & PET-Al-LDPE & $\begin{array}{r}\text { Total: } 127 \\
\text { Al: } 7.1\end{array}$ & Zip closure & $<0.02 \mathrm{~g}\left(100 \mathrm{in}^{2} \mathrm{~d}\right)^{-1^{\mathrm{b}}}$ & $14.5 \times 24$ & 1.2 \\
\hline h_Al3z & $\mathrm{CB} 400-528 \mathrm{~N}^{\mathrm{WP}}$ & PET-Al-LDPE & $\begin{array}{r}\text { Total: } 127 \\
\text { Al: } 7.1\end{array}$ & Zip closure & $<0.02 \mathrm{~g}\left(100 \mathrm{in}^{2} \mathrm{~d}\right)^{-1^{\mathrm{b}}}$ & $20 \times 26$ & 2.4 \\
\hline $\mathrm{Al} 3 \_\mathrm{t}$ & CB300-510NWP & PET-Al-LDPE & $\begin{array}{r}\text { Total: } 127 \\
\text { Al: } 7.1\end{array}$ & PTFE tape & $<0.02 \mathrm{~g}\left(100 \mathrm{in}^{2} \mathrm{~d}\right)^{-1^{\mathrm{b}}}$ & $20 \times 26$ & 2.4 \\
\hline Al3z_hs & CB400-420BRZ ${ }^{\mathrm{WP}}$ & PET-Al-LDPE & $\begin{array}{r}\text { Total: } 127 \\
\text { Al: } 7.1\end{array}$ & $\begin{array}{l}\text { Zip closure and } \\
\text { heat-sealed }\end{array}$ & $<0.02 \mathrm{~g}\left(100 \mathrm{in}^{2} \mathrm{~d}\right)^{-1^{\mathrm{b}}}$ & $14.5 \times 24$ & 1.2 \\
\hline
\end{tabular}

${ }^{a}$ At $85 \%$ RH, $23{ }^{\circ} \mathrm{C}$ (URL1, 2021). ${ }^{\mathrm{b}}$ At $90 \% \mathrm{RH}, 40{ }^{\circ} \mathrm{C}$ (Pacific Bag, Inc., Woodinville, WA, USA, personal communication, 2020). ${ }^{\text {ede }}$ Edeka, Germany (vendor). MIG Migros, Switzerland (vendor). Cof Cofresco, Minden, Germany. WP Weber Packaging, Güglingen, Germany. NA stands for not available.

sis, two reference standards were co-measured to account for potential instrument drift or unintended fluctuations in laboratory air temperature. Each time, these standards had been freshly prepared $2 \mathrm{~d}$ in advance. For this purpose, $5 \mathrm{~mL}$ of identical water aliquots had been filled into the bags with the lowest water loss rate observed in the first part of this study. Apart from that, this preparation followed the principle of identical treatment (PIT) between samples and standards. For each day, we calculated and report here the differences in raw isotope readings between the sample triplicates and respective standards.

\subsection{Data analysis}

We assumed that potential weight losses of the bags would occur solely due to evaporation and diffusion of water vapor out of partly gas-permeable bags, and isotope data of the liquid water reservoir would then follow a Rayleigh-type evolution (Lord Rayleigh, 1902). Thus, liquid water isotope signatures were calculated by using raw isotope readings of the bags' sampled headspace vapor and a linear relationship between the standards' headspace readings and referenced liquid water isotope values assuming a slope of 1 , which had been repeatedly confirmed in liquid water isotope analyses on the same instrument. Then, for oxygen $\left({ }^{18} \mathrm{O} /{ }^{16} \mathrm{O}\right)$ and hydrogen $\left({ }^{2} \mathrm{H} /{ }^{1} \mathrm{H}\right)$, isotope fractionation factors were determined by simulating the isotope ratio $R$ with the following approach:
$R=R_{0} \times f^{\alpha-1}$,

where subscript 0 refers to the start of the observations, $f$ is the remaining fraction of the water reservoir at the respective time of observation, and $\alpha$ is the isotopic fractionation factor between the liquid water reservoir and the evolving vapor (Majoube, 1971). Further, it holds that

$R=R_{\mathrm{std}} \times\left(1+\frac{\delta_{\mathrm{sam}}}{1000 \% \mathrm{o}}\right)$,

where $\delta$ denotes the isotope signature in delta notation, and the subscript std in this case refers to the respective international standard for oxygen and hydrogen stable isotope ratios, VSMOW (Craig, 1961).

We calculated the minimum sample bag headspace volume $V_{\mathrm{hsp}}$ necessary for precise replicate analysis of matrixbound water isotopes via DVE-LS using Eq. (3), where $n$ is the number of desired, safely possible measurement iterations and also accounts for occasionally necessary prolonged analyses, $q$ is the analyzer-demanded gas flow rate (in $\mathrm{mL} \mathrm{min}^{-1}$ ), and $t$ is the time period (in minutes) usually necessary for reaching a sufficiently long plateau during numerous DVE-LS analyses previously conducted in our laboratory: 
$V_{\mathrm{hsp}}=n \times q \times t$.

We calculated the minimum necessary liquid water reservoir contained in the sample of interest $V_{\mathrm{H}_{2} \mathrm{O} \text {,min }}$ using Eq. (4), where $\varepsilon\left(T_{\text {air }}\right)$ is the isotope enrichment at equilibration temperature (in \%ovsmow) (Clark and Fritz, 1997), $V_{\mathrm{H}_{2} \mathrm{O} \text {,eq is }}$ the liquid water equivalent of the water present in the vapor phase of the bag (e.g., in cubic meters), and $\Delta \delta_{\text {acc }}$ is the isotope-specific accepted measurement uncertainty (in \%ovsMOw) that must not be exceeded systematically.

$V_{\mathrm{H}_{2} \mathrm{O}, \min }=\frac{\varepsilon\left(T_{\mathrm{air}}\right) \times V_{\mathrm{H}_{2} \mathrm{O}, \mathrm{eq}}}{\Delta \delta_{\mathrm{acc}}}$

The isotope enrichment $\varepsilon$ was calculated using Eq. (5), where $\alpha$ is the temperature-dependent isotope equilibrium fractionation factor between liquid water and a corresponding vapor phase (Majoube, 1971).

$\varepsilon\left(T_{\text {air }}\right) \approx\left(\alpha\left(T_{\text {air }}\right)-1\right) \times 1000 \%$

The liquid water equivalent was calculated using Eq. (6), where $T_{\mathrm{K} \text {,air }}$ is the equilibration temperature (in kelvin), $V_{\mathrm{bag}}$ is the bag headspace volume (in cubic meters), $R$ is the gas constant, $p_{\text {air }}$ is air pressure, $M_{\mathrm{H}_{2} \mathrm{O}}$ is the molar mass of water, and $\rho_{\mathrm{H}_{2} \mathrm{O}}$ is the density of liquid water.

$V_{\mathrm{H}_{2} \mathrm{O}, \text { eq }}=\frac{V_{\text {bag }}}{\frac{R \times T_{\mathrm{K}, \text { air }}}{p_{\text {air }}}} \times \frac{E_{\mathrm{H}_{2} \mathrm{O}}\left(T_{\text {air }}\right)}{p_{\text {air }}} \times \frac{M_{\mathrm{H}_{2} \mathrm{O}}}{\rho_{\mathrm{H}_{2} \mathrm{O}}}$

The first term on the right side of this equation accounts for the ratio of the bag volume and the volume $1 \mathrm{~mol}$ of gas occupies under given conditions, the second term expresses the share that water vapor has of total molecules present in the gas phase, and the third term converts the previous ones from a mole number into a volume of liquid water. With $R=8.314 \mathrm{~J}(\mathrm{~mol} \mathrm{~K})^{-1}, \rho_{\mathrm{H}_{2} \mathrm{O}}=1000 \mathrm{~kg} \mathrm{~m}^{-3}$, and $M_{\mathrm{H}_{2} \mathrm{O}}=0.018 \mathrm{~kg} \mathrm{~mol}^{-1}$ and by canceling out the air pressure $p_{\text {air }}$, Eq. (6) simplifies to

$V_{\mathrm{H}_{2} \mathrm{O}, \text { eq }}=\frac{V_{\text {bag }} \times E_{\mathrm{H}_{2} \mathrm{O}}\left(T_{\text {air }}\right)}{T_{\mathrm{K}, \text { air }}} \times 2.165 \times 10^{-6} \mathrm{~K} \mathrm{~Pa}^{-1}$.

$E\left(T_{\text {air }}\right)$ is saturation vapor pressure (in pascals) as a function of air temperature (Foken, 2008). It is calculated with Eq. (8), where $T_{\text {air }}$ is air temperature (this time in degrees Celsius).

$E_{\mathrm{H}_{2} \mathrm{O}}=611.2 \times e^{\frac{17.62 \times T_{\text {air }}}{243.12+T_{\text {air }}}}$

Equation (9) describes the same physical relationship as Eq. (4). It is based on closed-system assumptions inside a sample container and the fact that the residual liquid water isotopic composition is systematically shifted towards "heavier" values when a significant fraction thereof $(1-f)$ saturates an initially dry atmosphere to achieve isotope equilibrium (see, e.g., line D of Fig. 2 in Gat, 1996). Assuming a linear relationship between the remaining water fraction $f$ and changes in its isotopic composition and applying the intercept theorem and mass balance considerations, we obtain

$\frac{\Delta \delta_{\mathrm{CS}}}{\varepsilon_{\mathrm{eq}}}=\frac{V_{\mathrm{H}_{2} \mathrm{O}, \mathrm{eq}}}{V_{\mathrm{H}_{2} \mathrm{O}, \mathrm{sam}}}=(1-f)$,

where $\Delta \delta_{\mathrm{cs}}$ is the systematic shift in both vapor and liquid water isotope signatures caused by equilibrium fractionation in a closed system, $\varepsilon_{\text {eq }}$ is the equilibrium isotope enrichment again (Eq. 5), $V_{\mathrm{H}_{2} \mathrm{O} \text {,eq }}$ is the evaporated water volume (Eqs. 6 and 7), and $V_{\mathrm{H}_{2} \mathrm{O} \text {,sam }}$ is the total liquid water volume initially present in a sample which is not directly measured or calculated but can usually be roughly estimated in the field when collecting samples.

Ratios of mean isotope enrichment rates were calculated as estimates of the slopes of so-called evaporation lines that water stable isotope data plot on in dual isotope space when affected by gradual evaporitic enrichment of heavy isotopes. We compared these to the ratio of deviations from unity of the model-derived isotope fractionation factors $\alpha$ (Eq. 1). Individually, these deviations yield the respective isotope enrichments (Eq. 5).

\section{Results}

\subsection{Empirical observations}

\subsubsection{Material selection}

The average area-normalized weight loss rates of the 10 tested bags varied by 3 orders of magnitude, ranging from

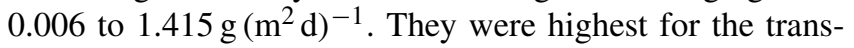
parent low-density polyethylene (LDPE) bag of low strength $(G \& G)$ and lowest for the heat-sealed bag that included one layer of aluminum (Al) foil (Al3z_hs). For non-metalized bags the weight loss rates were in the opposite order of their wall strengths. For metalized bags they were highest where the Al layer had been applied by a steaming process and lower in cases of laminated $\mathrm{Al}$ foil. For the latter, they were highest for zip-closed-only bags and lowest for the additionally heat-sealed bag, with the PTFE-taped bag (Al3_t) plotting in between, close to Al3z_hs. For the three Al-laminated bags with identical closures, differing only in their sizes, the largest one (h_Al3z) had a slightly lower weight loss rate than the other two (Al3z and s_Al3z), which were almost identical. The different lengths of the time series occurred because only few bag types were available at the beginning of the observations, and additional specimens $(+$ heat-sealing pliers) were found later and included. Observations were terminated when clear trends had become visible for all bags under investigation. Time series of weight losses are displayed with a synchronous start for better comparability of trends (Fig. 2). For all time series, clear linear relationships were found with coefficients of determination $\left(R^{2}\right)$ higher than 0.98 for those exceeding absolute weight losses of $0.2 \mathrm{~g}$. 


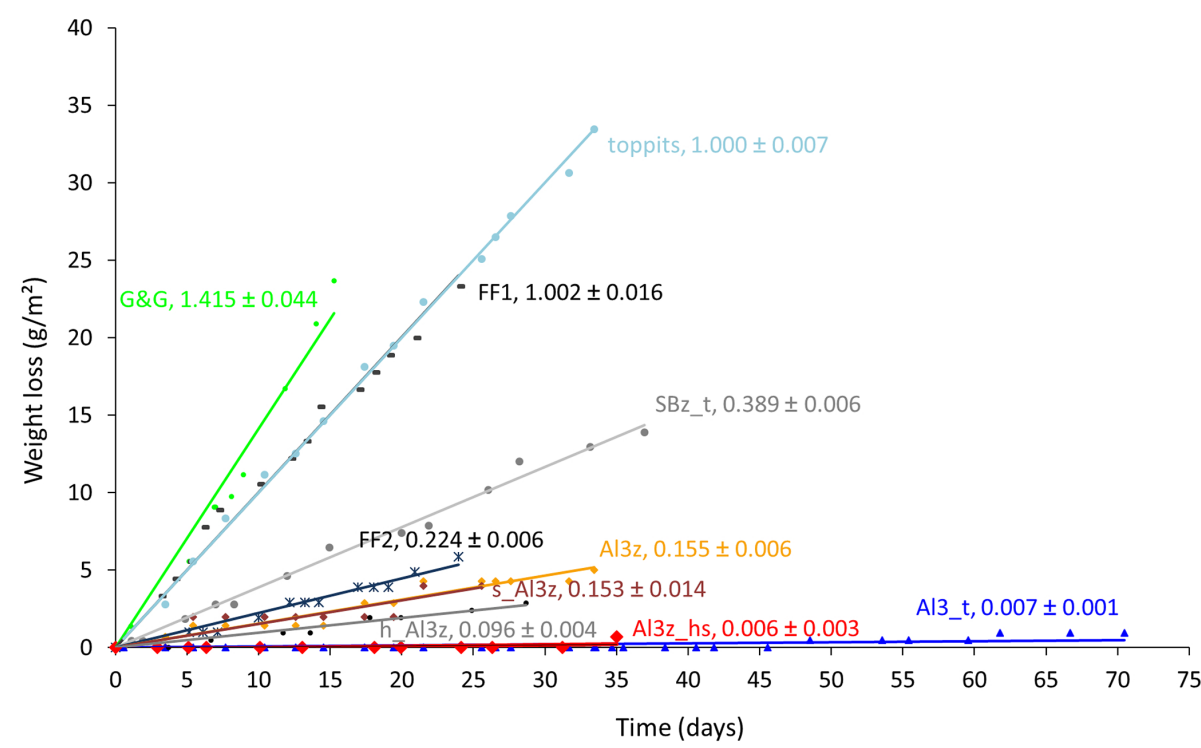

Figure 2. Time series of weight losses normalized to the surface areas of 10 different bags filled with moist soil. Numbers in line labels are slopes of the trend lines and indicate average weight loss rates and uncertainties in $\mathrm{g}\left(\mathrm{m}^{2} \mathrm{~d}\right)^{-1}$.

\subsubsection{Weight losses and stable isotope effects}

For further assessment we selected the Toppits ${ }^{\circledR}$ freezer bags and the Al-laminated bags with zip closure and a volume of $1.2 \mathrm{~L}$. Both bag types are available at reasonable costs: the former are sold by regular household supply stores (EUR 0.14 unit $^{-1}$ ), while the latter can be obtained from a specialty packaging wholesaler (see Table 1) (EUR 0.65 unit $^{-1}$ ). Toppits ${ }^{\circledR}$ freezer bags were used as stand-alone (single-layer, "toppits") and bag-in-bag (doublelayer, "toppits_double") versions. Al-laminated bags were used as zip-closed-only ("Al3z") and as zip-closed and additionally heat-sealed ("Al3z_hs") versions. This time, the area-normalized weight loss rate of toppits and $\mathrm{Al} 3 \mathrm{z}$ bags had decreased by $16.3 \%$ and $23.2 \%$, respectively, compared to the previous results, while it was - although on a low level - higher for Al3z_hs bags. Nonetheless, weight loss patterns were congruent in both parts of the study. Again, the highest weight loss rates were observed for transparent, non-metalized bags having the lowest barrier strengths (toppits), and the lowest weight loss rates were observed for Al-laminated, heat-sealed bags (Al3z_hs). On the final day of our experiment, mean weight losses reached $1.71 \mathrm{~g}$ and $0.90 \mathrm{~g}$ for single- and double-layer Toppits ${ }^{\circledR}$ bags, respectively. In the same order, these weight losses represent $34.1 \%$ and $17.9 \%$ of the weight of the water initially filled into the bags. For Al3z and Al3z_hs bags, we observed final average weight losses of 0.23 and $0.06 \mathrm{~g}$, which translate to $4.5 \%$ and $1.1 \%$, respectively. Averages and uncertainties in normalized weight loss rates for all bag versions can be found in Table 2. For transparent and Al-laminated bags mean standard deviations of triplicates were lower for the double-walled and more thoroughly closed version, respectively, and generally inconsistent over time.

Unlike weight loss data, temporal changes in isotope readings were not normalized to the bags' surface areas in order to enable direct comparison with generally accepted measurement uncertainties. Over the course of $28 \mathrm{~d}$, headspace vapor isotope readings changed steadily for three of the four bag versions. At the end of the observation period they deviated from initial readings on average by $+10.23 \%$, $+4.74 \%$ o, and $+1.37 \%$ o for $\delta^{18} \mathrm{O}$ and $+37.34 \%$ o, $+20.00 \%$, and $+2.78 \%$ or $\delta^{2} \mathrm{H}$ for toppits, toppits_double, and $\mathrm{Al} 3 \mathrm{z}$ bags, respectively. In the same order, changes in $\delta^{18} \mathrm{O}$ exceeded the standard deviation derived from replicates of the co-measured standards after 2,5 , and $21 \mathrm{~d}$, and changes in $\delta^{2} \mathrm{H}$ crossed this margin after 2,2 , and $28 \mathrm{~d}$. For heat-sealed Al-laminated bags (Al3z_hs), no trend exceeding these standard deviations within the observation period was found for either isotope signatures under investigation. Due to "noisiness" on day 1 , linear regression models were applied starting on day 2 (Fig. 4). Their slopes decreased with increasing barrier strengths in the case of Toppits ${ }^{\circledR}$ bags and more thorough closures in the case of Al-laminated bags. This pattern is consistent with water loss characteristics (Fig. 3). For each bag version investigated, the ratio of isotope enrichment rates, which yields the slope of a so-called evaporation line in dual isotope space, is consistently lower than 8 (which would have indicated isotope equilibrium). It is fairly equal for both freezer bag versions, considerably lower for AL3z bags, and even negative for Al3z_hs bags. For the latter the respective underlying average isotope enrichment rates are exceeded by their uncertainties. Absolute numbers and uncertainties in change rates of isotope readings can be found in Table 2 . 


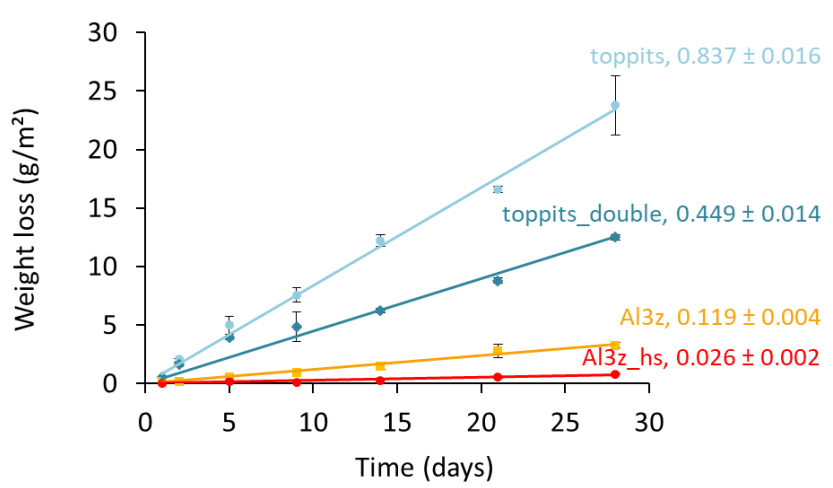

Figure 3. Time series of average weight losses normalized to the surface areas of single-layer (light-blue circles) and doublelayer (blue diamonds) Toppits ${ }^{\circledR}$ freezer bags as well as zip-closedonly (orange squares) and additionally heat-sealed (red circles) Allaminated bags. Numbers in line labels are slopes of the trend lines and indicate average weight loss rates and uncertainties in $\mathrm{g}\left(\mathrm{m}^{2} \mathrm{~d}\right)^{-1}$.

With only few exceptions (toppits: day 5 and 28), standard deviations of triplicate isotope analyses were smaller than the observed drift standard measurement uncertainty $(0.6 \%$ o for $\delta^{18} \mathrm{O}, 2.14 \%$ ofor $\left.\delta^{2} \mathrm{H}\right)$.

\subsection{Data analysis}

The outcome of the Rayleigh-type simulation (Eq. 1) of the calibrated liquid water isotope signatures obtained from the headspace vapor observations can be seen in Fig. 5. For all bag types and both isotope ratios investigated, the observed isotope evolutions do not exceed the quasi-linear part of a typical Rayleigh curve. For the Toppits ${ }^{\circledR}$ freezer bags isotope data plot along clear paths. For the Al-laminated bags, isotope data and remaining fraction data calculated from weight observations plot within very narrow ranges not displaying any distinct correlations or trends. The respective isotope fractionation factors were determined by minimizing the root mean square error (RMSE) between observed and simulated isotope data using Eq. (1) and the SOLVER function of the Microsoft ${ }^{\circledR}$ Excel software package. In the case of toppits bags, deviations from unity of the fractionation factors obtained this way (cf. Eq. 5) were about twice as high as the ones of toppits_double bags for both isotope ratios. The deviations from unity were highest for Al-laminated bags, with absolute values being inverted for Al3z_hs bags. Numerical values of all model-derived fractionation factors can be found in Table 2. RMSE values as functions of fractionation factors were calculated as a measure of parameter sensitivity and are shown in Fig. 6. Overall, we arbitrarily varied fractionation factors by \pm 1 relative to their respective RMSE-optimized values, which extends the range we consider physically possible. Over the entire range investigated, RMSE values displayed only the one minimum presented here for each bag type and isotope ratio. Minimum RMSE values as well as relative changes thereof were lowest for Al-laminated bags and highest for freezer bags for both isotope fractionation factors determined. The ratios of observed mean enrichment rates and the ratios of deviation from unity of the model-derived fractionation factors were in very good agreement in the case of toppits bags and differed most in the case of heat-sealed Al-laminated bags (Table 2).

Our calculation of minimum headspace volume (Eq. 3) accounts for $n=5$ replicates to be safely possible; the analyzerdemanded gas flow rate of $q=35 \mathrm{~mL} \mathrm{~min}^{-1}$; and $t=5 \mathrm{~min}$, which is usually necessary for reaching a sufficiently long plateau (e.g., $90 \mathrm{~s}$ ) in the observed data. Based on these numbers we obtain a volume of $875 \mathrm{~mL}$, which we round up to $1 \mathrm{~L}$ to have an additional safety margin and for practical reasons. Considering a sample bag with a headspace volume of $1 \mathrm{~L}$ and an equilibration temperature of $20^{\circ} \mathrm{C}$, we calculated that $17.24 \mu \mathrm{L}$ of liquid water fully saturates this headspace (Eqs. 6 and 7). At this temperature the isotope fractionation factor $\alpha$ is about 1.00981 for $\delta^{18} \mathrm{O}$ and 1.08521 for $\delta^{2} \mathrm{H}$, which translates to respective enrichments $(\varepsilon)$ of $9.81 \% \circ$ and $85.21 \%$ (Eq. 5). We assume accepted analytical uncertainties of $0.2 \%$ or $\delta^{18} \mathrm{O}$ and $1.0 \%$ or $\delta^{2} \mathrm{H}$ that should not be exceeded. These result in a minimum water volume of 0.85 or $1.47 \mathrm{~mL}$, respectively, which has to be contained in the collected samples (Eq. 4) and be able to exchange with the corresponding headspace during the projected equilibrium time.

\section{Discussion}

\subsection{Container material}

In the first part of this study we investigated 10 different bags of various materials and closure types regarding their capability to hold liquid water and water vapor and found a wide range of weight loss rates spanning 3 orders of magnitude. It seems reasonable to assume that all of the weight lost was water. The consistent linearity of the water loss characteristics observed over the course of several weeks indicates that, generally, export of water vapor was not limited by the total water content of the field-moist samples. Evaporation from gradually decreasing water reservoirs being the limiting factor would have resulted in corresponding decreases in water loss rates over time. Instead, water losses were constant, and thus persistent diffusion from well-maintained vapor reservoirs to ambient air through bag walls and closures can be deduced. For identical bag types (toppits, Al3z) different water loss rates were observed in the two parts of the study $\left(1.000\right.$ vs. 0.837 and 0.155 vs. $0.119 \mathrm{~g}\left(\mathrm{~m}^{2} \mathrm{~d}\right)^{-1}$, respectively). We relate this effect to the fact that the two parts of our study were conducted during different seasons (late winter and summer, respectively) under accordingly varying humidity conditions in the laboratory, where only the temperature was controlled but not the humidity. Notwithstand- 

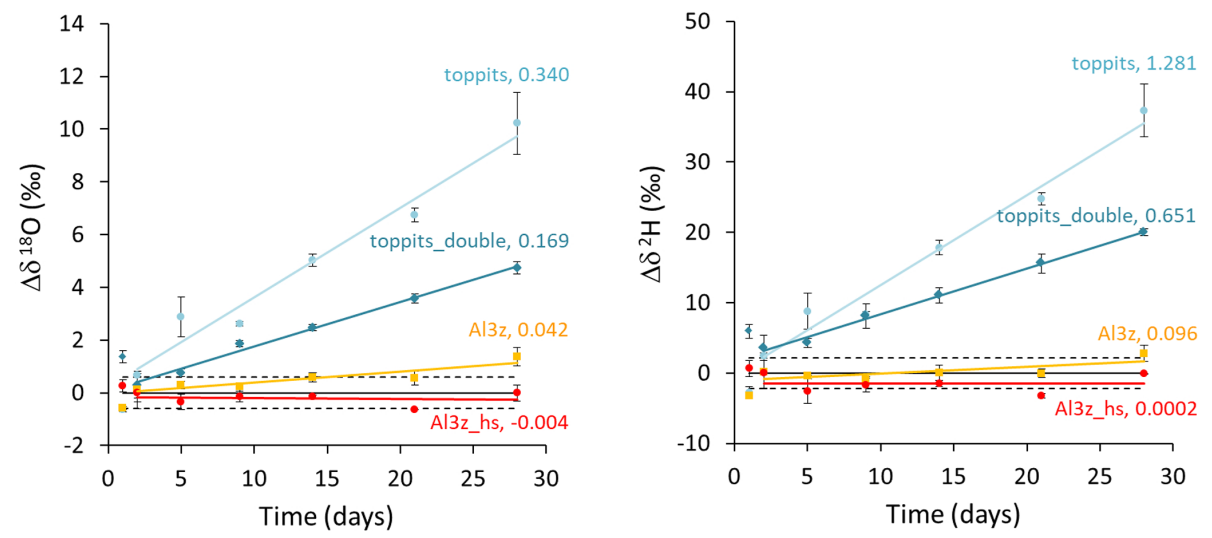

Figure 4. Time series of drift-corrected changes in headspace water vapor stable isotope readings observed in triplicates of single- (light-blue circles) and double-layer (blue diamonds) Toppits ${ }^{\circledR}$ freezer bags as well as of zip-closed-only (orange squares) and additionally heat-sealed (red circles) Al-laminated bags. Numbers in line labels are slopes of the trend lines and indicate average changes in isotope readings in $\% \mathrm{~d}^{-1}$ after day 1 . Horizontal lines represent baselines (solid lines) and reference water vapor standard deviations of $\pm 0.60 \%$ and $\pm 2.14 \% \circ$ for $\delta^{18} \mathrm{O}$ and $\delta^{2} \mathrm{H}$, respectively (dashed lines).

Table 2. Characteristics of changes in weight and isotope readings and model-derived isotope fractionation factors.

\begin{tabular}{|c|c|c|c|c|c|c|c|}
\hline Bag ID & $\begin{array}{r}\text { Weight loss } \\
\text { rate } \\
\left(\mathrm{g}\left(\mathrm{m}^{2} \mathrm{~d}\right)^{-1}\right)\end{array}$ & $\begin{array}{r}\delta^{18} \mathrm{O} \\
\text { enrichment } \\
\text { rate }\left(\% \circ \mathrm{d}^{-1}\right)\end{array}$ & $\begin{array}{r}\delta^{2} \mathrm{H} \text { enrichment } \\
\quad \text { rate }\left(\% o \mathrm{~d}^{-1}\right)\end{array}$ & $\begin{array}{r}\text { Ratio of } \\
\text { mean } \\
\text { enrichment } \\
\text { rates }\end{array}$ & $\begin{array}{r}\text { Model-derived } \\
\text { isotope } \\
\text { fractionation } \\
\text { factor } \alpha^{18} \mathrm{O}\end{array}$ & $\begin{array}{r}\text { Model-derived } \\
\text { isotope } \\
\text { fractionation } \\
\text { factor } \alpha^{2} \mathrm{H}\end{array}$ & $\begin{array}{r}\text { Ratio of } \\
\text { deviations } \\
\text { of } \alpha \text { from } \\
\text { unity }\end{array}$ \\
\hline toppit & $0.837 \pm 0.016$ & $0.340 \pm 0.021$ & $1.281 \pm 0.069$ & 3.77 & 0.97338 & 0.89753 & 3.85 \\
\hline toppits_double & $0.449 \pm 0.014$ & $0.169 \pm 0.007$ & $0.651 \pm 0.031$ & 3.85 & 0.98787 & 0.94192 & 4.79 \\
\hline Al3z & $0.119 \pm 0.004$ & $0.042 \pm 0.008$ & $0.0959 \pm 0.0353$ & 2.28 & 0.96119 & 0.86295 & 3.53 \\
\hline Al3z_hs & $0.026 \pm 0.002$ & $-0.004 \pm 0.009$ & $0.0002 \pm 0.0428$ & -0.05 & 1.04339 & 1.14501 & 3.34 \\
\hline
\end{tabular}

ing the initial use of a less precise scale, we could clearly show that only few of the tested bags were capable of reliably holding water vapor inside under ambient temperature conditions (Fig. 2) and are therefore suitable for the DVE-LS method, where the conservative storage of moist soil, rock, or plant samples is elementary.

Nonetheless, we further scrutinized not only Al-laminated bags but also transparent freezer bags. Similar to the Allaminated bags, they allow for easy handling and have therefore been used previously by our and other research groups (e.g., Garvelmann et al., 2012). Transparent freezer bags had been tested for the same purpose before with weight losses of only $0.06 \mathrm{~g}$ in the first $10 \mathrm{~d}$ (Hendry et al., 2015). However, it is unclear to what extent those bags and the ones tested here match in terms of material type and strength as we only tested standard freezer bags available in supermarkets and drugstores in Germany. We observed weight differences of up to $10 \%$ for seemingly similar empty freezer bags from different batches (data not shown). We attribute this to potential differences in the production process resulting in variable wall strengths or some kind of "age effect" caused by, for example, the outgassing of softeners or material degradation from UV impacts. Notably, the mean weight loss rate of toppits bags is about twice the mean weight loss rate of toppits_double bags $\left(0.837\right.$ vs. $0.449 \mathrm{~g}\left(\mathrm{~m}^{2} \mathrm{~d}\right)^{-1}$, respectively), which confirms that under identical environmental conditions the water vapor transmission rate is an inverse function of the material thickness. It is therefore quite plausible that different magnitudes of weight losses and isotope effects for seemingly similar bags have been found under fairly similar temperature and RH settings in previous studies and in this study.

Theoretical values for water vapor permeability were available for most materials used in this study. However, they had been determined under different temperature and $\mathrm{RH}$ settings presumably given different standardization requirements in different countries (Table 1). We assumed that the permeabilities are not affected by structural changes on the molecular level within the applied temperature ranges and thus can be normalized to any desired vapor pressure gradient. In doing so, we calculated water vapor permeabilities for all bags investigated in the first part of our study (data not shown) for the average temperature and RH conditions recorded in our laboratory. However, comparison of calculated and theoretical permeability values was only somewhat helpful as available values for LDPE did not include ma- 

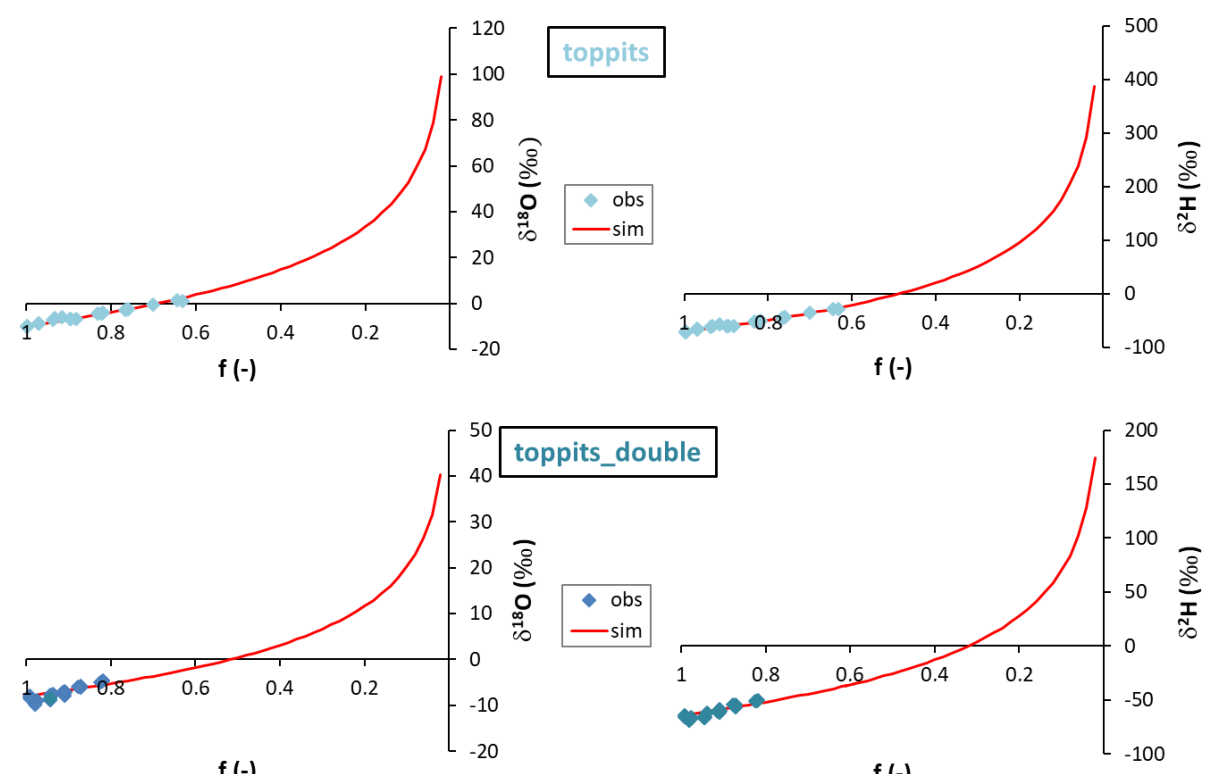

$f(-)$

$f(-)$
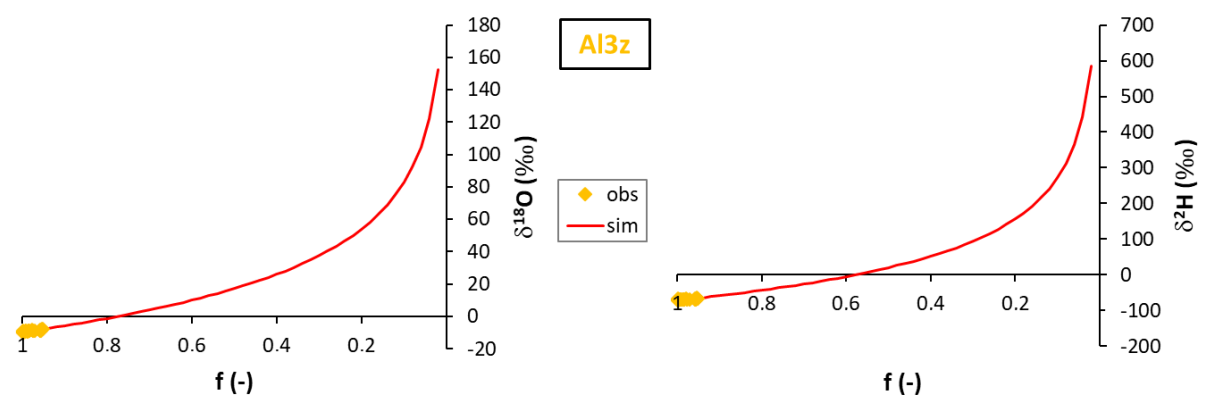

$f(-)$

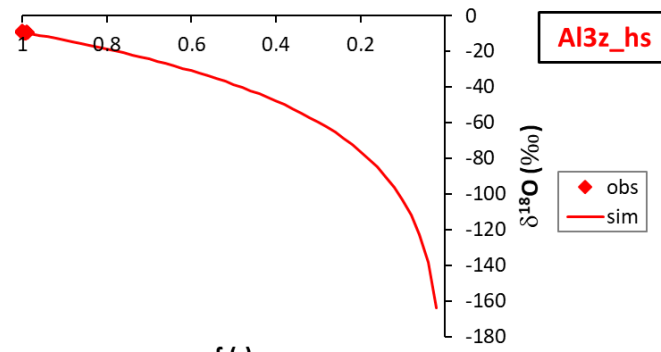

$f(-)$

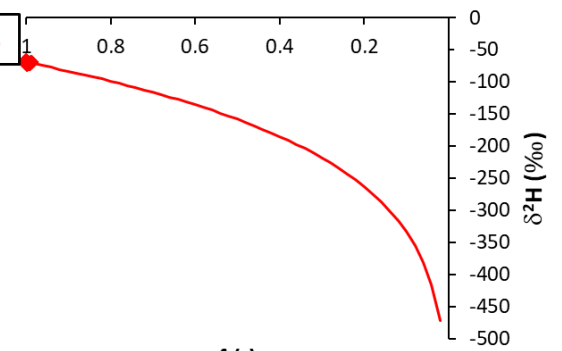

$f(-)$

Figure 5. Observations (diamonds; "obs") and Rayleigh-type simulations (red lines; "sim”) of liquid water $\delta^{18} \mathrm{O}$ (left column) and $\delta^{2} \mathrm{H}$ data (right column) obtained from single- (top row) and double-layer (second row) Toppits® freezer bags and zip-closed-only (third row) and additionally heat-sealed (bottom row) Al-laminated bags as functions of the respective residual water fractions $f$.

terial strength, and values for Al-laminated bags were only reported as "lower-than" expressions, which we consistently undercut. Further, we had assumed that in all cases vapor loss had occurred exclusively through the bags' entire wall areas despite the different tested closure types for Al-laminated bags and some bags lying on their sides or touching other surfaces.

Generally, evaporation is proportional to the saturation vapor pressure deficit expressed in absolute pressure units (e.g., hPa) (Dalton, 1802), which defines the gradient and thus the vapor flux. Under stable temperature conditions it is directly proportional to the saturation vapor pressure deficit, expressed in relative fractions of saturation vapor pressure $(1-\mathrm{RH}$, in percent). Having recorded RH in our laboratory, we observed extremes that translate to relative vapor pressure deficits of $88.2 \%$ and $16.9 \%$, which constitutes a maximum variation factor of 5.2. This factor is still larger than 1.5 when considering only the mean and standard deviation of RH. However, these numbers do not fully describe the variability in individual isotopologues' vapor pressures in the laboratory air. We are convinced that similar conditions hold for other laboratories as well. It is therefore impossible to fully con- 
(a)

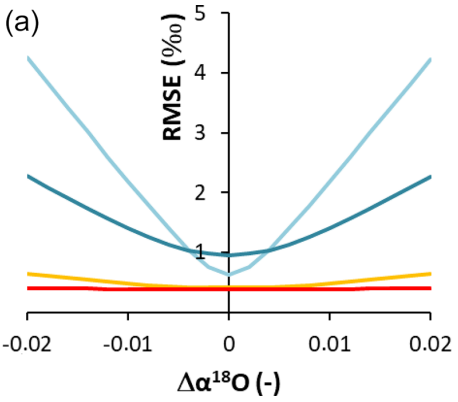

(b)

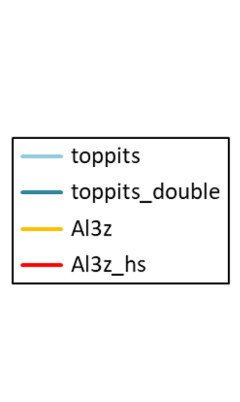

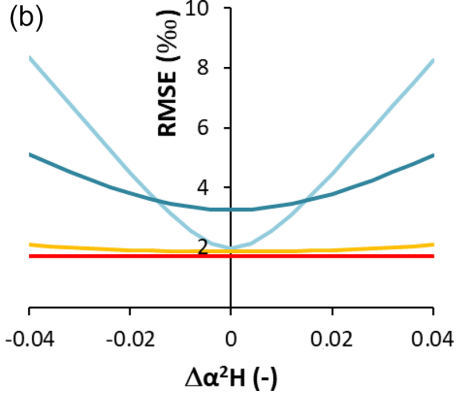

Figure 6. Absolute model RMSE values as functions of the absolute deviations ( $\Delta$ ) from the RMSE-optimized values of $\alpha^{18} \mathrm{O}(\mathbf{a})$ and $\alpha^{2} \mathrm{H}$ (b).

sider all relevant drivers of evaporation and thus isotope effects. However, we argue that this would be necessary when trying to obtain unflawed data from DVE-LS sample bags that fail to prevent significant water loss over the time of the respective isotope assays.

One argument for the use of transparent, yet gas- and thus vapor-permeable sample bags has been their capability to dampen potentially increased concentrations of $\mathrm{CO}_{2}$ caused by ongoing microbial activity in natural soil samples. Also significant levels of spectrally interfering VOCs that perhaps accompany plant water analysis might be leveled out. Yet, the complex field of plant metabolism and related VOC emissions is outside the scope of this study. Changes in the gas matrix have been demonstrated to affect isotope analyses on laser-based analyzers like the one used in this study (Gralher et al., 2016). Unlike the presence of, for example, alcohols, elevated levels of $\mathrm{CO}_{2}$ are not flagged by the analyzer's data post-processing software ChemCorrect ${ }^{\mathrm{TM}}$ (West et al., 2011). However, it has also been described how biases caused by the buildup of $\mathrm{CO}_{2}$ could be reliably corrected with reasonable effort using analyzer-recorded spectral variables only (Gralher et al., 2018). Besides, the fact that biogenic $\mathrm{CO}_{2}$ concentrations may be dampened in the case of gas-permeable bags does not guarantee that they are completely removed and will thus become irrelevant concerning analyzer-immanent gas matrix effects. This relativizes the presumed advantage of transparent, somewhat gas-permeable freezer bags for the DVE-LS method considering the potential large isotope effects due to water loss and related isotope fractionation.

Furthermore, using vapor-permeable sample bags means accepting a steady loss of water, i.e., a non-zero net vapor flux from the samples to ambient air. This also means accepting the fact that by definition no real equilibrium is reached prior to analysis. Instead, temporary steady-state conditions are reached which are variably close to the desired equilibrium. The deviation therefrom depends on the momentary water loss rate, while the duration is additionally a function of absolute sample water content. Both factors are usually unknown and likely variable between samples and relative to co-measured standards. Specifically, the ratio of mean en- richment rates (Table 2) and accepted uncertainty should not be taken for the calculation of generally applicable maximum storage times. The high uncertainties in underlying isotope readings indicate that a sufficient compliance with PIT cannot be assumed.

Throughout the second part of the study, measurements were performed on similar, but not identical bags in order to ensure their structural integrity during the entire storage time prior to isotope analyses. This explains why for triplicates of toppits bags standard deviations for both weight loss and headspace vapor isotope signatures did not steadily increase but varied over time (Figs. 3 and 4). It proves that water loss characteristics of similar bags can be variable. Using bags with structural differences revealed this way for the preparation of samples and calibration standards will then cause unnoticed violations of PIT. A correction of this additional error is not possible with reasonable effort, if at all.

Rayleigh-type simulations of isotope evolutions were performed on calibrated liquid water isotope signatures. They yielded fractionation factors that were consistently higher than those reported for kinetic fractionation for both isotope ratios investigated in this study (Gonfiantini, 1986). The deviations from unity of fractionation factors (cf. Eq. 5) derived from isotope and weight loss data of Al-laminated bags were higher than those derived from freezer bag data. The narrow ranges of underlying data in the case of Al-laminated bags caused relatively low parameter sensitivity, which can be deduced from the comparatively small changes in RMSE values (Fig. 6) and thus render the respective fractionation factors useless for interpretation despite their better absolute RMSE values. In the case of Al3z_hs the simulation of the quasi-constant weight and isotope data returned inverted model-derived fractionation factors. Clearly, these must be arbitrary artifacts as changes in the respective RMSE values as functions of applied fractionation factors are negligible over the entire range investigated. Physically - and hypothetically - inverted fractionation factors would mean that evaporation would release thermal energy instead of consuming it, thereby causing heavier isotopologues to be preferred in this process, which clearly contradicts any common (isotope) 
knowledge. In the case of freezer bags, model-derived fractionation factors displayed much higher sensitivities notwithstanding their somewhat larger minimum RMSE values. This indicates that in this case the applied Rayleigh model adequately represents the physical processes causing the observed changes in isotope readings. The wider ranges of underlying isotope and weight loss data of toppits bags are the reason for the higher respective parameter sensitivity. Especially in this case, we consider the good agreement between the ratio of mean isotope enrichment and the ratio of deviations from unity of model-derived fractionation factors (Table 2) to be proof of their plausibility.

Generally, deviations from unity of the fractionation factors were inversely correlated with wall strengths, i.e., diffusional barriers, which in the case of Al3z bags must have consisted mainly of the zip closure. The fractionation factors may thus be plausible, but they do not inherit any practical benefit as they should not be taken for, for example, correction schemes. They can only be taken as proof that water loss via, for example, liquid water dripping can be excluded, and instead a combination of isotope fractionating processes, namely evaporation and diffusion, occurred, and thus Rayleigh-type evolutions of water stable isotopes appeared. However, they have limited significance as the observed evolutions are still within the quasi-linear parts of typical Rayleigh curves. It should be noted that despite the higher isotope fractionation factors in the case of $\mathrm{Al} 3 \mathrm{z}$ bags, the very small overall water loss resulted in comparatively low enrichment of heavy isotopes on the timescale of our study, which must be of premier interest when conducting isotope studies.

\subsection{Container size}

We calculated the minimum headspace volume for DVE-LS sample containers to be $\sim 1 \mathrm{~L}$. This number is based on our analyzer's gas flow demand $\left(\sim 35 \mathrm{~mL} \mathrm{~min}^{-1}\right)$, its response time, and continuous vapor sampling. Provided full inflation, the suggested container size includes a safety margin as it accounts for occasionally necessary prolonged measurement durations, e.g., when aiming at specific, consistent standard deviation thresholds for vapor concentrations and isotope readings to be finally reached on the obtained data plateaus. The proposed bag size also enables replicate analyses on identical samples. This would be the case when the readings obtained in the first attempt are doubted for some reason and need to be confirmed. It would also be the case when some or all samples of the respective batch are expected to be affected by buildup of biogenic $\mathrm{CO}_{2}$, and repeated analyses are desired for applying the previously mentioned correction scheme (Gralher et al., 2018).

The bag size needs to be increased when larger-than-usual volumes of sample material are to be collected, e.g., in order to account for low water content (see next section) or when trying to balance unwanted spatial variability. Also, for isotope analyzers with higher gas flow settings (e.g., Los Gatos) it needs to be adapted accordingly. In extreme cases, a design different from the "normal" continuous and linear vapor sampling might be required. An irresolvable mismatch between vapor sample size and analyzer-demanded gas flow rate might call for, for example, circular (e.g., via sample loop, similar to Gaj et al., 2019) or discrete sampling (e.g., via gas-tight syringe). However, such modifications are outside the scope of this study. Notably, light-weight samples are sometimes required for logistical reasons, e.g., when samples are shipped via air freight or must be physically carried in large numbers through rough terrain by dedicated scientists. In a careful trade-off with the previously described safety precautions (to-be-enabled analysis duration and iterations), smaller sample bags (e.g., $0.5 \mathrm{~L}$ ) into which smallerthan-usual samples (see next section) can be collected might then be favorable.

\subsection{Sample size}

Regarding the proposed DVE-LS sample size, we agree with previous suggestions (Wassenaar et al., 2008, Hendry et al., 2015) that researchers should not aim at collecting a certain, standard sample volume but instead collect samples containing a minimum volume of water into the bags. Their suggestion of $3 \mathrm{~mL}$ was based on observations using double-freezerbagged samples of various artificially produced moisture contents where samples below $5 \%$ gravimetric water content revealed heavy-isotope enrichment exceeding the accepted measurement uncertainty. Unfortunately, no weight changes were reported for those samples. Thus, it cannot be fully excluded that the observed variations in isotopic composition were at least in part a result of water vapor loss to ambient air. We calculated the minimum necessary absolute water content to be $1.47 \mathrm{~mL}$ when using evaporation-safe bags of $1 \mathrm{~L}$ headspace volume. For liquid water standards, prepared for calibration and drift control purposes of DVE-LS samples, the same holds true. This means that they also need to consist of at least this water volume. In order to obtain accurate isotope data, we strongly suggest that this volume ratio should always be exceeded. This would, however, be violated when filling, for example, previously proposed Reliance ${ }^{\mathrm{TM}}$ water containers (Mattei et al., 2019) with only $20 \mathrm{~mL}$ of water.

Our suggested minimum volume ratio accounts for the fact that depending on the equilibration temperature, a defined amount of sample water will evaporate in order to saturate a given bag's headspace. Using heat-sealed Al-laminated sample bags with proven evaporation safety (Figs. 2 and 3), it seems reasonable to assume closed-system conditions once isotopic equilibria are established. Then, Eq. (9) can be applied and solved for $\Delta \delta_{\mathrm{cs}}$ in order to calculate the impact of a too-small sample liquid water reservoir on isotope data accuracy. At any given stable temperature the equilibrium isotope enrichment and the evaporated water volume can be treated 
as constants. Thus, a larger amount of sample water will lead to a smaller systemic effect on isotope readings and vice versa. We admit that this is probably of minor importance in the case of typical mid-latitude fine-textured soil samples usually containing sufficient water given the dimensions of common soil coring devices. However, it could easily become relevant in the context of arid and/or coarse-textured soils or compartment-specific sampling of plants, especially when investigating individual specimens. In either case, we recommend in situ analysis of volumetric water content when collecting soil samples. To be on the safe side for either isotope ratio, no less than $2 \mathrm{~mL}$ of sample-contained water should be aimed for, e.g., in order to account for likely bag and inflation volume uncertainties. This translates to, for example, a minimum of $10 \mathrm{~mL}$ of soil with a volumetric water content of $0.2 \mathrm{~m}^{3} \mathrm{~m}^{-3}$. Having investigated only pure water samples, we cannot say if this advice is exhaustive also for samples with high solute concentrations or very low volumetric water content. It has been demonstrated that high concentrations of salt (Horita, 2005, or references therein; Koehler et al., 2013) or very low moisture content (Gaj et al., 2019) can have a significant impact on water-vapor isotope equilibrium fractionation. Such effects potentially present in pristine samples are hard to mimic though, as would be necessary for the preparation of appropriate calibration standards. Future studies aiming at expanding the applicability of the DVE-LS method may find appropriate means to correct for these issues.

It should be noted that the impact of this "small-sample" effect on data accuracy depends on the investigated isotopologues. The ratio of typically accepted measurement uncertainty relative to the isotope enrichment is smaller and therefore less favorable in the case of $\delta^{2} \mathrm{H}$ than for $\delta^{18} \mathrm{O}$ (e.g., $1.0 \%$ o $/ 85.21 \%$ vs. $0.2 \%$ \% $/ 9.81 \%$, respectively, at $20{ }^{\circ} \mathrm{C}$ ). This means that in the case of $\delta^{2} \mathrm{H}$ the evaporation of a fraction of a little over $1 \%$ will already lead to measurable effects. This fraction is well below the threshold of $2 \%$ which was suggested by Araguás-Araguás et al. (1995) for acceptable kinetic water loss. Further, the effect increases with temperature as the relative increase in saturation vapor pressure (Eq. 8) is stronger than the respective decrease in isotope enrichment (Eq. 5). Finally, this shift is fully effective when calibration of raw vapor isotope readings is not facilitated by means of similarly affected calibration standards but rather by means of calculated water-vapor isotope equilibrium fractionation (e.g., Majoube, 1971). Nonetheless, even when employing standards for calibration purposes researchers should not aim at matching the size of (too)small samples and standards as it appears to be impossible to establish fully identical conditions (PIT) in terms of water content, evaporation-effective interfacial area, equilibration time, headspace inflation volume, etc. Rather, they should try to avoid the small-sample effect through collection of samples sufficing the suggested volume ratio $(<500: 1)$ of bag headspace and matrix-bound water reservoir.
We did not try to quantify this effect mathematically for the case of vapor-permeable sample containers as we do not consider them to be closed systems (Figs. 2 and 3) and thus cannot recommend their use anyway. The modelderived isotope fractionation factors determined for the Toppits ${ }^{\circledR}$ bags (Fig. 5, Table 2) are considerably more different from unity than the ones reported for equilibrium fractionation at ambient temperature (Majoube, 1971). Presumably, this translates to even less favorable accepted-uncertainty-toenrichment ratios (Eqs. 5 and 9). Clearly, even for largerthan-recommended water volumes contained in a sample (here: $5 \mathrm{~mL}$ ), continuous enrichment of heavy isotopes and thus measurable effects on isotope readings quickly appear (Fig. 4). For the case of vapor-permeable sample bags, this renders the above considerations based on closed-system assumptions obsolete.

\subsection{Equilibrium time}

When DVE-LS samples are left for isothermal equilibration, vapor exchange between a sample's liquid water reservoir and the respective bag's headspace atmosphere will first include only the sample's outermost water "layers". Relative to the water volume necessary for saturation of the headspace volume (Eqs. 6 and 7), this fraction of an entire sample's liquid water reservoir might be small enough for a temporary small-sample effect to evolve (see previous section). This results in initial isotope readings to be shifted towards higher values. It is followed by a downshift and the disappearance of the small-sample effect due to inward migration of the exchange zones via diffusion in the samples' liquid and vapor phases. We take this as evidence that the determination of sufficiently long DVE-LS equilibration times should not rely solely on the bulk vapor saturation (representing almost exclusively $\mathrm{H}_{2}^{16} \mathrm{O}$ ) of a sample container's headspace, which likely happens within a few hours not only in the case of pure water samples (David et al., 2018; Pratt et al., 2016). We argue that it is impossible to follow the principle of identical treatment (PIT) when applying such short equilibration times. Even if there is a strict consistency of equilibration times between all samples and relative to comeasured calibration standards, there will still be structural differences resulting in different kinetics of all isotopologues (e.g., $\mathrm{H}_{2}^{18} \mathrm{O}, \mathrm{HD}^{16} \mathrm{O}$ ) prior to equilibria that represent sufficiently large fractions of the samples' and standards' liquid phases (Fig. 4). We therefore suggest that DVE-LS equilibration times for soil samples should be at least $2 \mathrm{~d}$ to allow for sufficiently large representative elementary volume (REV) (Bachmat and Bear, 1987) to evolve. When inward diffusion is impeded, for example in the case of clayey soil samples, equilibration times should be extended, as already pointed out by Wassenaar et al. (2008). But this is safely possible only with evaporation-safe sample containers.

Obviously, the maximum time that should be allowed for isothermal equilibration is limited. In the case of double- 
layered transparent bags and water volumes of $5 \mathrm{~mL}$ we observed isotope enrichment beyond acceptable limits within $2-5 \mathrm{~d}$, depending on the investigated isotope ratio (Fig. 4). Unfortunately, this happens to be the time period suggested for minimum equilibration. Further, this does not consider smaller samples or a given sample's pre-equilibration history during transport and storage. We argue that even collective storage of such samples in coolers (e.g., Wassenaar et al., 2008) or other confined spaces is not an entirely safe practice. Despite presumed high relative humidity and thus restricted net evaporation in such spaces, isotope exchange between samples would still take place over time via the vapor phase due to heavier isotopologues' individual vapor pressure gradients. This ultimately erases the isotope ratio differences of interest (cf. Ingraham and Criss, 1993, 1998). Generally, storage times are not always predictable and thus should be planned with a buffer due to, for example, unforeseeable instrument failures, restricted analytical capacities, or illness of laboratory staff. Prolonged storage times must also be considered in the case of extensive isotope assays and/or field campaigns in remote areas. Therefore, we consider transparent bags to be not suitable for DVE-LS analysis.

Over the entire course of our experiments, we did not see significant changes in isotope readings in the case of heatsealed Al-laminated bags filled with $5 \mathrm{~mL}$ of distilled water. For natural soil samples, however, it has been shown that extensive equilibration times may lead to, for example, buildup of unwanted, spectrally interfering methane. This must be taken into account for ongoing microbial activity in samples with high organic carbon content from, for example, the uppermost layers of a forest soil. (Gralher et al., 2018). Fortunately, significant methane buildup can easily be avoided as it occurs only under anoxic conditions. These can be prevented for quite some time by using well-balanced container sizes (see Eq. 9) and oxygen-bearing inflation atmospheres (e.g., synthetic air). Then, equilibration times exceeding by far those proposed for clayey samples (Wassenaar et al., 2008) are safely possible. We suggest that such samples should be somewhat disintegrated inside the sampling bags in order to increase the exchange-relevant sample surface area. Given the generally low hydraulic conductivity of clay and the naturally occurring long-term persistence of fine-scale isotope variations inside such media, we assume that full equilibration between an entire clayey sample's liquid water reservoir and the sample bag's headspace vapor is not likely to happen on the timescale of normal DVE-LS assays. Rather, a liquid water fraction (i.e., the REV) as large as possible being effective and thus avoiding the small-sample effect can be pursued in this case.

The case of zip-closed-only Al3z bags can be seen as a representation of sample transport and storage. Comparison of zip-closed-only Al3z bags and heat-sealed zip-closed Al3z_hs bags allows the assessment of the negative impacts of sample transport and storage on vapor loss as heat-sealing is generally not applied before inflation. Here, vapor loss must have happened mostly through the zip closure given that the integer bag walls are identical to the ones of Al3z_hs bags. Probably due to the small database $(n=3)$, we were unable to find a meaningful correlation $\left(R^{2}=0.15\right)$ between the lengths of zip closures (Table 1) and weight loss rates. Nonetheless, we assume that feasible storage times without significant heavy-isotope enrichment inside such samples are considerably longer than the duration of this study as stored samples are generally kept deflated and rolled up, thus restricting potential vapor diffusion even more.

\section{Conclusion}

We provided empirical evidence as well as physically wellfounded considerations that should help users of the direct vapor equilibration (DVE-LS) method to plan or optimize the parameters of their matrix-bound water isotope sampling and analysis campaigns. Specifically, we scrutinized the critical previously unresolved aspects, container material, and equilibration time as well as the volumes of container headspace and sample-contained water including their optimum ratio, which had not been determined before. Regarding sample containers, we convincingly demonstrated the limits of frequently used transparent Toppits ${ }^{\circledR}$ freezer bags, which were strongly contrasted by Al-laminated bags, losing virtually no water and ensuring consistent isotope readings over unprecedentedly long periods when properly heat-sealed. For the first time, Al-laminated bags allow the applied equilibration time to be adapted exclusively to sample requirements instead of accepting reduced data quality in a trade-off with material shortcomings as immanent in the case of freezer bags. In order to prevent evaporation, Al-laminated bags do not require extra measures. Nonetheless, cooling samples prior to inflation is advisable in order to reduce microbial activity as well as the associated buildup of $\mathrm{CO}_{2}$ and changes in the gas matrix. Ultimately, this prevents reducing environments and the production of spectrally interfering gases. Freezing samples for this purpose, however, cannot be recommended as this might destroy soil aggregates and microstructures. The resulting effect on isotope readings has not yet been investigated systematically.

Regarding the volumes of available container headspace and sample-contained liquid water necessary for precise and accurate analyses we suggest a ratio of no more than $500: 1$. For absolute numbers of the container headspace volume the analyzer gas flow demand is authoritative. As a standard operation protocol, we recommend users of the DVELS method who are working with isotope analyzers similar to ours to employ heat-sealed Al-laminated sample bags of $1 \mathrm{~L}$ volume, to allow for equilibration times of no less than $2 \mathrm{~d}$, and to collect samples containing at least $2 \mathrm{~mL}$ of water. We are confident that our findings will help to further strengthen the DVE-LS method's capability of quickly delivering trust- 
worthy and intercomparable isotope data. Moreover, we feel the need to raise awareness for the method's various complex aspects and underlying physical principles that have to be considered in order to not violate the principle of identical treatment. Future efforts should focus on amendments towards better applicability for geologic or organic samples emitting spectrally interfering VOCs. Calibration strategies that fully mimic the effects potentially accompanying natural soil aggregates including extreme conditions regarding, for example, salinity or aridity are also still missing.

Data availability. Data are available from the authors upon request.

Author contributions. BH and BG jointly designed the experiments and performed the data analysis. $\mathrm{BH}$ conducted the experiments; BG conceived the theoretical parts and wrote the first draft of the manuscript. BG and $\mathrm{BH}$ prepared the manuscript. MW contributed with advice and reviewed the manuscript.

Competing interests. The authors declare that they have no conflict of interest.

Disclaimer. Publisher's note: Copernicus Publications remains neutral with regard to jurisdictional claims in published maps and institutional affiliations.

Acknowledgements. Special thanks go to Ralph Schwab, manager of the local fish counter, who kindly supported this project in the very beginning by happily providing all types of material typically used in his store for fish and meat packaging and lending us in good faith the required heat-sealing device. We would also like to thank the people from Weber Packaging for providing various free samples of their products.

Financial support. Barbara Herbstritt was supported through the Bio-TGW project (grant no. 02WGW1538B) funded by the German Federal Ministry of Education and Research (BMBF).

This open-access publication was funded by the University of Freiburg.

Review statement. This paper was edited by Brian Berkowitz and reviewed by Leonard Wassenaar and one anonymous referee.

\section{References}

Araguás-Araguás, L., Rozanski, K., Gonfiantini, R., and Louvat, D.: Isotope effects accompanying vacuum extraction of soil water for stable isotope analyses, J. Hydrol., 168, 159-171, https://doi.org/10.1016/0022-1694(94)02636-P, 1995.

Bachmat, Y. and Bear, J.: On the Concept and Size of a Representative Elementary Volume (Rev), in: Advances in Transport Phenomena in Porous Media, edited by: Bear, J. and Corapcioglu, M. Y., NATO ASI Series (Series E: Applied Sciences), 128, Springer, Dordrecht, https://doi.org/10.1007/978-94-009-36256_1, 1987.

Bertrand, G., Masini, J., Goldscheider, N., Meeks, J., Lavastre, V., Celle-Jeanton, H., Gobat, J.-M., and Hunkeler, D.: Determination of spatiotemporal variability of tree water uptake using stable isotopes $\left(\delta^{18} \mathrm{O}, \delta^{2} \mathrm{H}\right)$ in an alluvial system supplied by a highaltitude watershed, Pfyn forest, Switzerland, Ecohydrology, 7, 319-333, https://doi.org/10.1002/eco.1347, 2014.

Boumaiza, L., Chesnaux, R., Walter, J., and Stumpp, C.: Assessing groundwater recharge and transpiration in a humid northern region dominated by snowmelt using vadose-zone depth profiles, Hydrogeol. J., 28, 2315-2329, https://doi.org/10.1007/s10040020-02204-z, 2020

Brand, W. A., Geilmann, H., Crosson, E. R., and Rella, C. W.: Cavity ring-down spectroscopy versus high-temperature conversion isotope ratio mass spectrometry; a case study on $\delta^{2} \mathrm{H}$ and $\delta^{18} \mathrm{O}$ of pure water samples and alcohol/water mixtures, Rapid Commun. Mass Sp., 23, 1879-1884, https://doi.org/10.1002/rcm.4083, 2009.

Chesnaux, R. and Stumpp, C.: Advantages and challenges of using soil water isotopes to assess groundwater recharge dominated by snowmelt at a field study located in Canada, Hydrol. Sci. J., 63, 679-695, https://doi.org/10.1080/02626667.2018.1442577, 2018.

Clark, I. D. and Fritz, P.: Environmental Isotopes in Hydrogeology, Lewis, Boca Raton, 348 pp., https://doi.org/10.1201/9781482242911, 1997.

Craig, H.: Standard for reporting concentrations of deuterium and oxygen-18 in natural waters, Science, 133, 1833-1834, https://doi.org/10.1126/science.133.3467.1833, 1961.

Dalton, J.: Experimental Essays on the Constitution of Mixed Gases: On the Force of Steam or Vapour from Water or Other Liquids in Different Temperatures, Both in a Torricelli Vacuum and in Air; on Evaporation; and on Expansion of Gases by Heat, Memoirs of the Literary and Philosophical Society of Manchester, 5, 536-602, 1802.

David, K., Timms, W., Hughes, C. E., Crawford, J., and McGeeney, D.: Application of the pore water stable isotope method and hydrogeological approaches to characterise a wetland system, Hydrol. Earth Syst. Sci., 22, 6023-6041, https://doi.org/10.5194/hess-22-6023-2018, 2018.

Filippini, M., Stumpp, C., Nijenhuis, I., Richnow, H. H., and Gargini, A.: Evaluation of aquifer recharge and vulnerability in an alluvial lowland using environmental tracers, J. Hydrol., 529, 1657-1668, https://doi.org/10.1016/j.jhydrol.2015.07.055, 2015.

Foken, T.: Angewandte Meteorologie, Springer-Verlag, Berlin, 325 pp., https://doi.org/10.1007/978-3-642-25525-0_8, 2008.

Gaj, M., Lamparter, A., Woche, S. K., Bachmann, J., McDonnell, J. J., and Stange, C. F.: The role of matric potential, solid interfacial chemistry, and wettability on iso- 
topic equilibrium fractionation, Vadose Zone J., 18, 180083, https://doi.org/10.2136/vzj2018.04.0083, 2019.

Garvelmann, J., Külls, C., and Weiler, M.: A porewater-based stable isotope approach for the investigation of subsurface hydrological processes, Hydrol. Earth Syst. Sci., 16, 631-640, https://doi.org/10.5194/hess-16-631-2012, 2012.

Gat, J. R.: Oxygen and hydrogen isotopes in the hydrologic cycle, Annu. Rev. Earth Pl. Sc., 24, 225-262, https://doi.org/10.1146/annurev.earth.24.1.225, 1996.

Gralher, B., Herbstritt, B., Weiler, M., Wassenaar, L. I., and Stumpp, C.: Correcting laser-based water stable isotope readings biased by carrier gas changes, Environ. Sci. Technol., 50, 7074-7081, https://doi.org/10.1021/acs.est.6b01124, 2016.

Gralher, B., Herbstritt, B., Weiler, M., Wassenaar, L. I., and Stumpp, C.: Correcting for biogenic gas matrix effects on laser-based pore water-vapor stable isotope measurements, Vadose Zone J., 17, 170157, https://doi.org/10.2136/vzj2017.08.0157, 2018.

Gonfiantini, R.: Environmental isotopes in lake studies, in: Handbook of environmental isotope geochemistry, edited by: Fritz, P. and Fontes, J. C., 2, 113-168, https://doi.org/10.1016/B978-0444-42225-5.50008-5, 1986.

Harrington, G. A., Gardner, W. P., Smerdon, B. D., and Hendry, M. J.: Palaeohydrogeological insights from natural tracer profiles in aquitard porewater, Great Artesian Basin, Australia, Water Resour. Res., 49, 4054-4070, https://doi.org/10.1002/wrcr.20327, 2013.

Hendry, M. J. and Wassenaar, L. I.: Inferring Heterogeneity in Aquitards Using High-Resolution $\delta \mathrm{D}$ and $\delta^{18} \mathrm{O}$ Profiles, Groundwater, 47, 639-645, https://doi.org/10.1111/j.17456584.2009.00564.x, 2009.

Hendry, M. J., Barbour, S. L., Zettl, J., Chostner, V., and Wassenaar, L. I.: Controls on the long-term downward transport of $\delta^{2} \mathrm{H}$ of water in a regionally extensive, twolayered aquitard system, Water Resour. Res., 47, W06505, https://doi.org/10.1029/2010WR010044, 2011a.

Hendry, M. J., Richman, B., and Wassenaar, L. I.: Correcting for methane interferences on $\delta^{2} \mathrm{H}$ and $\delta^{18} \mathrm{O}$ measurements in pore water using $\mathrm{H}_{2} \mathrm{O}_{\text {(liquid) }}-\mathrm{H}_{2} \mathrm{O}_{\text {(vapor) }}$ equilibration laser spectroscopy., Anal. Chem., 83, 5789-5796, https://doi.org/10.1021/ac201341p, 2011b.

Hendry, M. J. and Wassenaar, L. I.: Millennial-scale diffusive migration of solutes in thick clay-rich aquitards: evidence from multiple environmental tracers, Hydrogeol. J., 19, 259-270, https://doi.org/10.1007/s10040-010-0647-4, 2011.

Hendry, M. J., Barbour, S. L., Novakowski, K., and Wassenaar, L. I.: Paleohydrogeology of the Cretaceous sediments of the Williston Basin using stable isotopes of water, Water Resour. Res., 49, 4580-4592, https://doi.org/10.1002/wrcr.20321, 2013.

Hendry, M. J., Schmeling, E., Wassenaar, L. I., Barbour, S. L., and Pratt, D.: Determining the stable isotope composition of pore water from saturated and unsaturated zone core: improvements to the direct vapour equilibration laser spectrometry method, Hydrol. Earth Syst. Sci., 19, 4427-4440, https://doi.org/10.5194/hess-19-4427-2015, 2015.

Herbstritt, B., Gralher, B., and Weiler, M.: Continuous in situ measurements of stable isotopes in liquid water, Water Resour. Res., 48, W03601, https://doi.org/10.1029/2011WR011369, 2012.

Horita, J.: Saline waters, in: Isotopes in the Water Cycle - Past, Present and Future of a Developing Science, edited by: Aggar- wal, P. K., Gat, J. R., and Froehlich, K. F. O., Springer, Doordrecht, the Netherlands, 381 pp., https://doi.org/10.1007/1-40203023-1_17, 2005.

Ingraham, N. L. and Criss, R. E.: Effects of surface area and volume on the rate of isotopic exchange between water and water vapor, J. Geophys. Res.-Atmos., 98, 20547-20553, https://doi.org/10.1029/93jd01735, 1993.

Ingraham, N. L. and Criss, R. E.: The effect of vapor pressure on the rate of isotopic exchange between water and water vapor, Chem. Geol., 150, 287-292, https://doi.org/10.1016/s00092541(98)00109-0, 1998.

Kleine, L., Tetzlaff, D., Smith, A., Wang, H., and Soulsby, C.: Using water stable isotopes to understand evaporation, moisture stress, and re-wetting in catchment forest and grassland soils of the summer drought of 2018, Hydrol. Earth Syst. Sci., 24, 3737-3752, https://doi.org/10.5194/hess-24-3737-2020, 2020.

Koehler, G. and Wassenaar, L. I.: Realtime Stable Isotope Monitoring of Natural Waters by Parallel-Flow Laser Spectroscopy, Anal. Chem., 83, 913-919, https://doi.org/10.1021/ac102584q, 2011.

Koehler, G., Wassenaar, L. I., and Hendry, J.: Measurement of stable isotope activities in saline aqueous solutions using optical spectroscopy methods, Isotopes in environmental and health studies, 49, 378-386, https://doi.org/10.1080/10256016.2013.815183, 2013.

Rayleigh, Lord O. M. F. R. S.: LIX. On the distillation of binary mixtures, The London, Edinburgh, and Dublin Philosophical Magazine and Journal of Science, 4, 521-537, https://doi.org/10.1080/14786440209462876, 1902.

Majoube M. F.: Fractionnement en oxygène-18 et en deuterium entre l'eau et sa vapeur, J. Chem. Phys., 58, 1423-1436, 1971.

Malowany, K., Stix, J., Van Pelt, A., and Lucic, G.: $\mathrm{H}_{2} \mathrm{~S}$ interference on $\mathrm{CO}_{2}$ isotopic measurements using a Picarro G1101-i cavity ring-down spectrometer, Atmos. Meas. Tech., 8, 40754082, https://doi.org/10.5194/amt-8-4075-2015, 2015.

Martín-Gómez, P., Barbeta, A., Voltas, J., Peñuelas, J., Dennis, K., Palacio, S., Dawson, T. E., and Ferrio, J. P.: Isotoperatio infrared spectroscopy: a reliable tool for the investigation of plant-water sources?, New Phytol, 207, 914-927, https://doi.org/10.1111/nph.13376, 2015.

Mattei, A., Barbecot, F., Guillon, S., Goblet, P., Hélie, J. F., and Meyzonnat, G.: Improved accuracy and precision of water stable isotope measurements using the direct vapour equilibration method, Rapid Commun. Mass Sp., 33, 1613-1622, https://doi.org/10.1002/rcm.8494, 2019.

Mattei, A., Barbecot, F., Goblet, P., and Guillon, S.: Pore water isotope fingerprints to understand the spatiotemporal groundwater recharge variability in ungauged watersheds, Vadose Zone J., 19, e20066, https://doi.org/10.1002/vzj2.20066, 2020.

Millar, C., Pratt, D., Schneider, D. J., and McDonnell, J. J.: A comparison of extraction systems for plant water stable isotope analysis, Rapid Commun. Mass Sp., 32, 1031-1044, https://doi.org/10.1002/rcm.8136, 2018.

Millar, C., Pratt, D., Schneider, D. J., Koehler, G., and McDonnell, J. J.: Further experiments comparing direct vapor equilibration and cryogenic vacuum distillation for plant water stable isotope analysis, Rapid Commun. Mass Sp., 1, 19-05-P, https://doi.org/10.1002/rcm.8530, 2019. 
Mueller, M. H., Alaoui, A., Kuells, C., Leistert, H., Meusburger, K., Stumpp, C., Weiler, M., and Alewell, C.: Tracking water pathways in steep hillslopes by $\delta^{18} \mathrm{O}$ depth profiles of soil water, J. Hydrol., 519, 340-352, https://doi.org/10.1016/j.jhydrol.2014.07.031, 2014.

Munksgaard, N. C., Wurster, C. M., and Bird, M. I.: Continuous analysis of $\delta^{18} \mathrm{O}$ and $\delta \mathrm{D}$ values of water by diffusion sampling cavity ring-down spectrometry: a novel sampling device for unattended field monitoring of precipitation, ground and surface waters, Rapid Commun. Mass Sp., 25, 3706-3712, https://doi.org/10.1002/rcm.5282, 2011.

Nakata, K., Hasegawa, T., Oyama, T., and Miyakawa, K.: Evaluation of $\delta^{2} \mathrm{H}$ and $\delta^{18} \mathrm{O}$ of water in pores extracted by compression method - effects of closed pores and comparison to direct vapor equilibration and laser spectrometry method, J. Hydrol., 561, 547-556, https://doi.org/10.1016/j.jhydrol.2018.03.058, 2018.

Oerter, E. J., Perelet, A., Pardyjak, E., and Bowen, G.: Membrane inlet laser spectroscopy to measure $\mathrm{H}$ and $\mathrm{O}$ stable isotope compositions of soil and sediment pore water with high sample throughput, Rapid Commun. Mass Sp., 31, 75-84, https://doi.org/10.1002/rcm.7768, 2016.

Pratt, D. L., Lu, M., Barbour, S. L., and Hendry, M. J.: An evaluation of materials and methods for vapour measurement of the isotopic composition of pore water in deep, unsaturated zones, Isot. Environ. Healt. S., 52, 529-543, https://doi.org/10.1080/10256016.2016.1151423, 2016.

Rothfuss, Y., Vereecken, H., and Brüggemann, N.: Monitoring water stable isotopic composition in soils using gas-permeable tubing and infrared laser absorption spectroscopy, Water Resour. Res., 49, 3747-3755, https://doi.org/10.1002/wrcr.20311, 2013.

Smith, A., Tetzlaff, D., Kleine, L., Maneta, M. P., and Soulsby, C.: Isotope-aided modelling of ecohydrologic fluxes and water ages under mixed land use in Central Europe: The 2018 drought and its recovery, Hydrol. Process., 34, 3406-3425, https://doi.org/10.1002/hyp.13838, 2020.

Sprenger, M., Herbstritt, B., and Weiler, M.: Established methods and new opportunities for pore water stable isotope analysis, Hydrol. Process., 29, 5174-5192, https://doi.org/10.1002/hyp.10643, 2015a.
Sprenger, M., Volkmann, T. H. M., Blume, T., and Weiler, M.: Estimating flow and transport parameters in the unsaturated zone with pore water stable isotopes, Hydrol. Earth Syst. Sci., 19, 2617-2635, https://doi.org/10.5194/hess-19-2617-2015, 2015 b.

Stumpp, C. and Hendry, M. J.: Spatial and temporal dynamics of water flow and solute transport in a heterogeneous glacial till: The application of high-resolution profiles of $\delta^{18} \mathrm{O}$ and $\delta^{2} \mathrm{H}$ in pore waters, J. Hydrol., 438-439, 203-214, https://doi.org/10.1016/j.jhydrol.2012.03.024, 2012.

URL1: Polymer Service GmbH, Merseburg, Germany: https://wiki. polymerservice-merseburg.de/index.php/Barriere-Kunststoffe, last access: 21 September 2021.

Volkmann, T. H. M. and Weiler, M.: Continual in situ monitoring of pore water stable isotopes in the subsurface, Hydrol. Earth Syst. Sci., 18, 1819-1833, https://doi.org/10.5194/hess-18-1819-2014, 2014.

Volkmann, T. H. M., Kühnhammer, K., Herbstritt, B., Gessler, A., and Weiler, M.: A method for in situ monitoring of the isotope composition of tree xylem water using laser spectroscopy, Plant Cell Environ., 39, 2055-2063, https://doi.org/10.1111/pce.12725, 2016.

Wang, H., Si, B., Pratt, D., Li, H., and Ma, X.: Calibration method affects the measured $\delta^{2} \mathrm{H}$ and $\delta^{18} \mathrm{O}$ in soil water by direct $\mathrm{H}_{2} \mathrm{O}_{\text {liquid }}-\mathrm{H}_{2} \mathrm{O}_{\text {vapour }}$ equilibration with laser spectroscopy, Hydrol. Process., 9, 1-11, https://doi.org/10.1002/hyp.13606, 2019.

Wassenaar, L. I., Hendry, M. J., Chostner, V. L., and Lis, G. P.: High resolution pore water $\delta^{2} \mathrm{H}$ and $\delta^{18} \mathrm{O}$ measurements by $\mathrm{H}_{2} \mathrm{O}_{\text {(liquid) }}-\mathrm{H}_{2} \mathrm{O}_{\text {(vapor) }}$ equilibration laser spectroscopy, Environ. Sci. Technol., 42, 9262-9267, https://doi.org/10.1021/es802065s, 2008.

Werner, R. A. and Brand, W. A.: Referencing strategies and techniques in stable isotope ratio analysis, Rapid Commun. Mass Sp., 15, 501-519, https://doi.org/10.1002/rcm.258, 2001.

West, A. G., Goldsmith, G. R., Matimati, I., and Dawson, T. E.: Spectral analysis software improves confidence in plant and soil water stable isotope analyses performed by isotope ratio infrared spectroscopy (IRIS), Rapid Commun. Mass Sp., 25, 2268-2274, https://doi.org/10.1002/rcm.5126, 2011. 